Article

\title{
Hydrothermal Synthesis of $\mathrm{rGO}^{-\mathrm{TiO}_{2}}$ Composites as High-Performance UV Photocatalysts for Ethylparaben Degradation
}

\author{
Miller Ruidíaz-Martínez ${ }^{1}$, Miguel A. Álvarez ${ }^{1, * \mathbb{D}}$, María Victoria López-Ramón ${ }^{1, *(D)}$, \\ Guillermo Cruz-Quesada ${ }^{1} \mathbb{D}$, José Rivera-Utrilla ${ }^{2}$ and Manuel Sánchez-Polo ${ }^{2}$ \\ 1 Department of Inorganic and Organic Chemistry, Faculty of Experimental Science, University of Jaen, \\ 23071 Jaen, Spain; miller.ruidiaz@ctb.edu.co (M.R.-M.); gcq00004@red.ujaen.es (G.C.-Q.) \\ 2 Department of Inorganic Chemistry, Faculty of Science, University of Granada, 18071 Granada, Spain; \\ jrivera@ugr.es (J.R.-U.); mansanch@ugr.es (M.S.-P.) \\ * Correspondence: malvarez@ujaen.es (M.A.Á.); mvlro@ujaen.es (M.V.L.-R.); \\ Tel.: +34-953-212750 (M.A.Á.); +34-953-212747 (M.V.L.-R.)
}

Received: 10 April 2020; Accepted: 6 May 2020; Published: 8 May 2020

\begin{abstract}
A series of reduced graphene oxide- $\mathrm{TiO}_{2}$ composites $\left(\mathrm{rGO}-\mathrm{TiO}_{2}\right)$ were prepared by hydrothermal treatment using graphite and titanium isopropoxide as raw materials. The structural, surface, electronic, and optical properties of the prepared composites were extensively characterized by $\mathrm{N}_{2}$ adsorption, FTIR, XRD, XPS, Raman spectroscopy, and DRS. GO was found to be effectively reduced and $\mathrm{TiO}_{2}$ to be in pure anatase phase in all composites obtained. Finally, experiments were performed to evaluate the effectiveness of these new materials as photocatalysts in the degradation of ethylparaben (EtP) by UV radiation. According to the band-gap energies obtained (ranging between $3.09 \mathrm{eV}$ for $4 \% \mathrm{rGO}-\mathrm{TiO}_{2}$ to $2.55 \mathrm{eV}$ for $30 \% \mathrm{rGO}-\mathrm{TiO}_{2}$ ), the $\mathrm{rGO}-\mathrm{TiO}_{2}$ composites behave as semiconductor materials. The photocatalytic activity is highest with a rGO content of 7 wt \% $\left(7 \% \mathrm{rGO}-\mathrm{TiO}_{2}\right)$, being higher than observed for pure $\mathrm{TiO}_{2}\left(\mathrm{E}_{\mathrm{g}}=3.20 \mathrm{eV}\right)$ and achieving $98.6 \% \mathrm{EtP}$ degradation after only 40 min of treatment. However, the degradation yield decreases with higher percentages of rGO. Comparison with rGO-P25 composites showed that a better photocatalytic performance in EtP degradation is obtained with synthesized $\mathrm{TiO}_{2}\left(\mathrm{rGO}-\mathrm{TiO}_{2}\right)$, probably due to the presence of the rutile phase (14.1 wt \%) in commercial P25.
\end{abstract}

Keywords: $\mathrm{rGO}^{-\mathrm{TiO}_{2}}$ nanocomposites; ethylparaben; ultraviolet radiation; photocatalysis

\section{Introduction}

Pharmaceutical and personal care products are extensively used worldwide and continuously released through wastewaters. These emerging pollutants cannot generally be removed by conventional wastewater treatment processes, and they have been found in treated waters and treatment plant sludge at low concentrations (ppb or ppm) [1].

Parabens are esters of p-hydroxybenzoic acid, with an alkyl or benzyl group, widely used as antimicrobial agents and preservatives in pharmaceutical, cosmetic, and food products [1]. The European Union has limited the concentration of parabens in cosmetic products to a maximum of $0.4 \%(\mathrm{p} / \mathrm{p})$ for individual parabens and $0.8 \%(\mathrm{p} / \mathrm{p})$, expressed as $\mathrm{p}$-hydroxybenzoic acid, for paraben mixtures [2]. Although these composites are readily biodegradable under aerobic conditions, they can be considered as "pseudo-persistent" pollutants due to their high consumption and continuous release in the environment.

Parabens are endocrine disruptors, and their high estrogenicity has led to their implication in some cases of breast cancer [3] and male sterility [4]. Skin can also absorb parabens from cosmetic 
products and may cause skin allergies [4]. Parabens contain phenolic hydroxyl groups that can readily react with free chloride, producing halogenated by-products. Chlorinated parabens have been detected in wastewaters, swimming pools, and rivers, although not yet in drinking water. These chlorinated by-products are more stable and persistent than progenitor species, and further studies are needed to elucidate their toxicity [5].

Given the increasing presence of these composites in natural waters, their potentially hazardous nature, and the low effectiveness of municipal wastewater treatment processes for their removal, there is considerable research interest in developing methods for their adequate degradation in wastewaters to avoid their release into the environment. Biological treatments can achieve this objective but are slow, taking at least five days to degrade parabens [6]. Adsorption is also frequently used for this purpose [7-9], but it is non-destructive and merely transfers pollutants from one phase to another.

Numerous advanced oxidation processes (AOPs) have been proposed to remove parabens from waters, including the Fenton process [10,11], electrochemical oxidation [12], simple ozonation [13,14], photolytic and photocatalytic oxidation [15-17], photosonochemical degradation [18], and photocatalytic ozonation [19], among others. Heterogeneous photocatalysis is considered one of the most effective AOPs for organic pollutant degradation [20] due to its high percentage degradation, effective mineralization, and low cost. This process requires photocatalysts with a wide photoabsorption range, good stability, high charge separation efficiency, and excellent redox properties. It is difficult to meet these requirements using a monocomponent photocatalyst. However, composite materials, such as those formed by graphene oxide (GO) and $\mathrm{TiO}_{2}$, can overcome the limitations of monocomponent photocatalysts by increasing the charge separation and the redox capacity [21].

$\mathrm{TiO}_{2}$ is used in a wide range of applications in different fields, including energy [22] and the environment [23], thanks to its low cost, easy management, chemical stability, and good optical and electronic properties [24]; however, it has a low quantum performance, mainly due to the recombination of electron-positive hole pairs. Therefore, major efforts have been made to prepare $\mathrm{TiO}_{2}$-based composite materials that can reduce electron-positive hole recombination. Graphene and its derivatives, such as $\mathrm{GO}$, have been proposed as among the most promising candidates for developing photo-efficient catalyst composites. The combination of $\mathrm{TiO}_{2}$ with graphene derivatives generates a synergic effect that potentially improves organic pollutant degradation due to improved adsorption capacity and efficient interface electron transfer between phases in the composite [25].

Numerous authors have studied $\mathrm{TiO}_{2}$ as photocatalyst to remove individual parabens from aqueous solutions [26-28]. Other catalysts used in paraben photodegradation have been $\mathrm{ZnO}$ [29], $\mathrm{Bi}_{4} \mathrm{O}_{5} \mathrm{I}_{2} / \mathrm{Bi}_{5} \mathrm{O}_{7} \mathrm{I}$ [30], $\mathrm{CoO}_{x} / \mathrm{BiVO}_{4}$ [31], $\mathrm{Ag}_{3} \mathrm{PO}_{4}$ [32], Al-doped- $\mathrm{TiO}_{2}$ [33], Fe-doped- $\mathrm{WO}_{3}$ [34], BiOI-hidrogel [35], and I-doped- $\mathrm{Bi}_{4} \mathrm{O}_{5} \mathrm{Br}_{2}$ [36].

$\mathrm{GO} / \mathrm{TiO}_{2}$ composite materials have been used in the degradation of dyes [37-39], pharmaceuticals [37], and pesticides [25]. However, there has been no report to date on their use in the degradation of parabens under UV radiation.

The characteristics that determine the behavior of photocatalysts are directly related to their structure and composition. The physicochemical characterization of composite materials is essential to correlate their catalytic behavior with their structure and physicochemical properties. Numerous techniques are available for the characterization of photocatalysts, yielding extensive information on their morphological, chemical, and electronic properties [40].

With this background, the objective of this study was to obtain a series of reduced graphene oxide (rGO)- $\mathrm{TiO}_{2}$ composites with different $\mathrm{rGO}$ contents by means of hydrothermal synthesis. All of these materials were exhaustively characterized in order to correlate their structural, chemical, electronic, and optical properties with their photoactivity in the UV radiation-induced degradation of organic pollutants in aqueous solutions. Surface area and porosity were determined by $\mathrm{N}_{2}$ adsorption and crystalline structure by X-ray diffraction (XRD). The dispersion and chemical nature of the catalysts were studied using Fourier transforming-infrared (FTIR) spectroscopy, Raman spectroscopy, X-ray photoelectron spectroscopy (XPS), and thermogravimetric analysis (TGA). Finally, their optical 
properties were analyzed by diffuse reflectance spectroscopy (DRS). Ethylparaben (EtP) was selected as model pollutant to investigate and compare the photocatalytic activity of the catalysts under study and to analyze the influence of their rGO content.

\section{Results}

\subsection{Porosity and Surface Area}

The performance of a photocatalyst can be improved by increasing its surface area and pore volume, increasing the adsorption of pollutant molecules, fast transport of products, and the separation of electron-positive hole pairs. Table 1 displays the textural characteristics of $\mathrm{rGO}^{-\mathrm{TiO}_{2}}$ and $\mathrm{rGO}-\mathrm{P} 25$ samples. $\mathrm{TiO}_{2}$ has higher $\mathrm{S}_{\mathrm{BET}}\left(81.5 \mathrm{~m}^{2} / \mathrm{g}\right), \mathrm{V}_{0}\left(0.030 \mathrm{~cm}^{3} / \mathrm{g}\right)$, and $\mathrm{V}_{0.95}\left(0.375 \mathrm{~cm}^{3} / \mathrm{g}\right)$ values in comparison to $\mathrm{P} 25\left(57.0 \mathrm{~m}^{2} / \mathrm{g}, 0.020 \mathrm{~cm}^{3} / \mathrm{g}\right.$, and $0.138 \mathrm{~cm}^{3} / \mathrm{g}$, respectively), possibly attributable to the smaller size of $\mathrm{TiO}_{2}$ nanoparticles in comparison to P25, as confirmed by XRD results. Incorporation of rGO sheets significantly increases the surface area and pore volume of composites in comparison to $\mathrm{TiO}_{2}$ alone, with the consequent decrease in mean micropore width $\left(\mathrm{L}_{0}\right)$ and increase in characteristic adsorption energy $\left(E_{0}\right)$ as the amount of rGO in the nanocomposite is enhanced. This change in porosity takes place because the incorporation of reduced graphene oxide hampers the agglomeration of $\mathrm{TiO}_{2}$ nanoparticles, which augments the surface area. $\mathrm{rGO}-\mathrm{TiO}_{2}$ composites have a larger surface area and porosity in comparison to rGO-P25 composites throughout the $\mathrm{rGO} \%$ range.

Table 1. Textural characteristics of $\mathrm{rGO}-\mathrm{TiO}_{2}$ and $\mathrm{rGO}-\mathrm{P} 25$ composites.

\begin{tabular}{|c|c|c|c|c|c|}
\hline Sample & $\begin{array}{l}S_{B E T}{ }^{a} \\
\left(\mathrm{~m}^{2} / g\right)\end{array}$ & $\begin{array}{c}V_{0} b \\
\left(\mathrm{~cm}^{3} / g\right)\end{array}$ & $\begin{array}{l}V_{0.95}{ }^{c} \\
\left(\mathrm{~cm}^{3} / \mathrm{g}\right)\end{array}$ & $\begin{array}{c}E_{0} d \\
(k J / m o l)\end{array}$ & $\begin{array}{l}\mathrm{L}_{0}{ }^{\mathrm{e}} \\
(\mathrm{nm})\end{array}$ \\
\hline $\mathrm{TiO}_{2}$ & 81.5 & 0.030 & 0.375 & 12.9 & 1.86 \\
\hline $4 \% \mathrm{rGO}-\mathrm{TiO}_{2}$ & 89.1 & 0.032 & 0.289 & 12.7 & 1.89 \\
\hline $7 \%$ rGO-TiO 2 & 97.7 & 0.036 & 0.242 & 14.1 & 1.70 \\
\hline $10 \%$ rGO-TiO 2 & 106.3 & 0.039 & 0.282 & 14.2 & 1.69 \\
\hline $30 \%$ rGO-TiO 2 & 141.1 & 0.051 & 0.273 & 15.2 & 1.58 \\
\hline P25 & 57.0 & 0.020 & 0.138 & 15.9 & 1.52 \\
\hline $4 \%$ rGO-P25 & 62.0 & 0.023 & 0.157 & 16.1 & 1.49 \\
\hline 7\%rGO-P25 & 66.8 & 0.024 & 0.171 & 16.4 & 1.46 \\
\hline $10 \%$ rGO-P25 & 71.4 & 0.026 & 0.190 & 16.8 & 1.42 \\
\hline $30 \%$ rGO-P25 & 115.9 & 0.043 & 0.236 & 17.9 & 1.37 \\
\hline
\end{tabular}

a Surface area according to $\mathrm{N}_{2}$ adsorption isotherms at $-196^{\circ} \mathrm{C} .{ }^{\mathrm{b}}$ Micropore volume from DR equation applied to $\mathrm{N}_{2}$ adsorption isotherms at $-196^{\circ} \mathrm{C} .{ }^{\mathrm{c}}$ Total pore volume from $\mathrm{N}_{2}$ adsorption isotherms at $-196^{\circ} \mathrm{C}$ and 0.95 relative pressure. ${ }^{\mathrm{d}}$ Characteristic adsorption energy from DR equation applied to $\mathrm{N}_{2}$ adsorption isotherms at $-196{ }^{\circ} \mathrm{C}$. ${ }^{\mathrm{e}}$ Mean micropore width from DR equation applied to $\mathrm{N}_{2}$ adsorption isotherms at $-196^{\circ} \mathrm{C}$.

\subsection{Thermogravimetric Analysis}

Figure 1 depicts thermogravimetric analysis curves for $\mathrm{TiO}_{2}$ and composite materials obtained in air atmosphere up to a temperature of $800^{\circ} \mathrm{C}$, showing four mass loss regions. The curves reveal an initial mass loss from 35 to $200{ }^{\circ} \mathrm{C}$, corresponding to dehydration and related to the elimination of adsorbed water molecules from the surface; the second loss, between 200 and $325^{\circ} \mathrm{C}$, corresponds to the decomposition of labile oxygenated groups bound to GO sheets; the third loss, between 325 and $600{ }^{\circ} \mathrm{C}$, corresponds to the combustion of carbon and more stable oxygenated groups [37,41]; and the fourth, between 600 and $800{ }^{\circ} \mathrm{C}$, corresponds to the dehydroxylation process. The rGO (\%) content of composites was calculated by subtracting the mass loss of $\mathrm{TiO}_{2}$ alone from the mass loss of rGO-TiO ${ }_{2}$, obtaining $3.7 \%$ for $4 \%$ rGO-TiO $2,6.9 \%$ for $7 \%$ rGO-TiO $2,9.4 \%$ for $10 \%$ rGO- $-\mathrm{TiO}_{2}$, and $28.3 \%$ for $30 \%$ rGO- $\mathrm{TiO}_{2}$. 


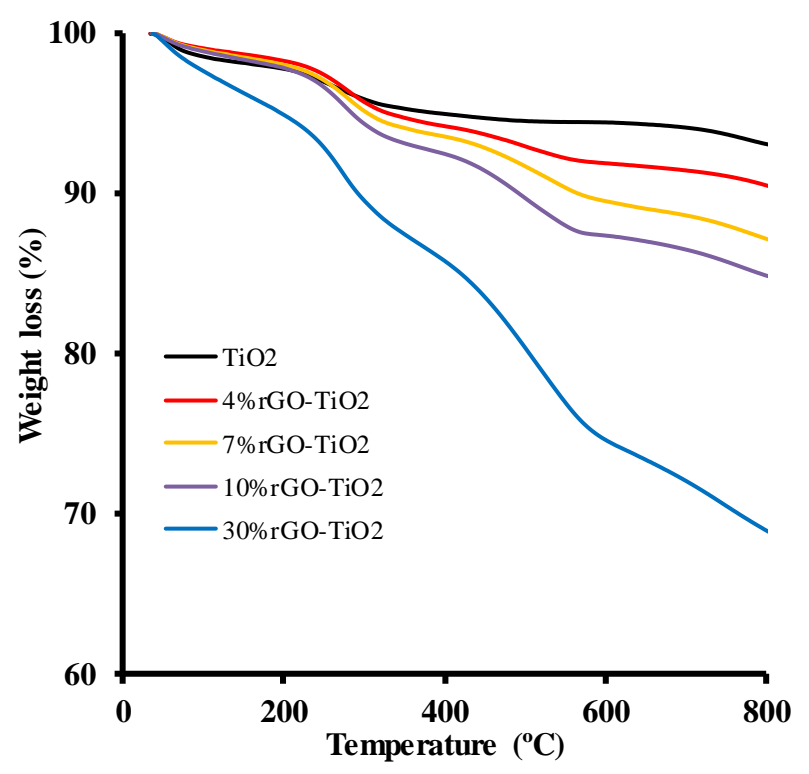

Figure 1. Thermogravimetric analysis curves for $\mathrm{TiO}_{2}$ and $\mathrm{x} \% \mathrm{rGO}-\mathrm{TiO}_{2}$.

Figure S1 (in Supplementary Material) depicts the thermogravimetric analysis curves for P25 and $\mathrm{x} \%$ rGO-P25 composites. The rGO content of the composites is $4.6 \%$ for $4 \%$ rGO-P25, $7.4 \%$ for $7 \%$ rGO-P25, 10.8\% for 10\% rGO-P25, and 28.1\% for 30\% rGO-P25.

\subsection{X-ray Diffraction Analysis}

Figure 2 depicts the diffractograms for graphite, GO, and rGO. Graphite shows a pronounced diffraction peak centered at $2 \theta=26.56^{\circ}$, corresponding to the (002) plane and indicating a high degree of crystallinity, with an interplanar distance of $0.336 \mathrm{~nm}$ (obtained by applying Bragg's law). Graphite peaks were identified using the JCPDS file ${ }^{\circ}$ 75-1621.

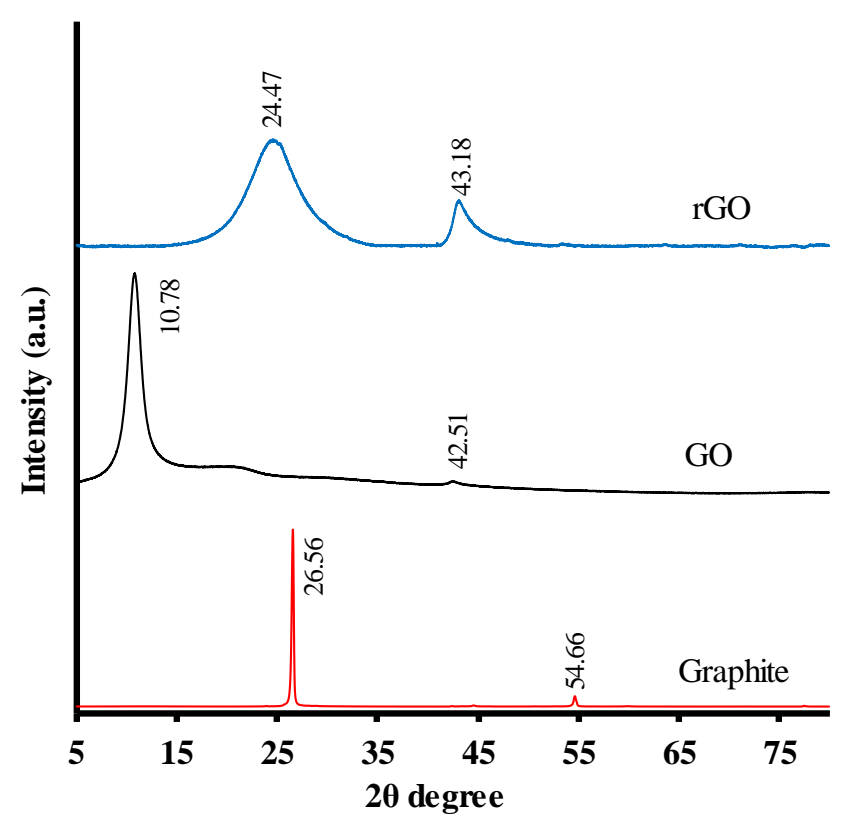

Figure 2. X-ray diffractogram for graphite, GO, and rGO.

The GO diffractogram shows only two peaks, at $10.78^{\circ}$ and $42.51^{\circ}$. Differences with the graphite diffractogram indicate that the graphite structure was modified by oxidation. The peak at $26.56^{\circ}(002)$ for graphite is shifted to $10.78^{\circ}$ in the $\mathrm{XRD}$ for $\mathrm{GO}$, this results from the incorporation of functional 
groups containing oxygen (hydroxyl, carbonyl, carboxylic, and epoxide groups) [42] in basal graphite sheets, increasing interplanar separation $[43,44]$. Individual GO sheets are expected to be thicker than in the original graphene due to the presence of oxygen-containing functional groups bound to both sides of the sheets and the roughness at atomic scale that arises from structural defects ( $\mathrm{sp}^{3}$ bond) generated in the originally flat graphene sheets [45].

Application of the Bragg equation to the diffraction peak (001) for GO at $10.78^{\circ}$ yields a value of $0.820 \mathrm{~nm}$, more than doubling the interplanar distance in comparison to the original graphite. The intense peak at $26.56^{\circ}$, characteristic of graphite, is completely absent in the XRD for GO. A low intensity peak appears at $42.51^{\circ}$, associated with plane (100) of the honeycomb hexagonal structure of graphite, also indicating the reaction effect. This peak (100) remains after oxidation and, alongside the disappearance of 002 , indicates the loss of crystallinity through the generation of defects in the structure [46].

The rGO sample diffractogram shows a wide peak centered at $24.47^{\circ}$, indicating a poor sheet ordering along the stacking direction [41]. This finding is related to the exfoliation and reduction of GO by the elimination of interspersed water and surface oxygenated groups. The interplanar distance is slightly larger in $\mathrm{rGO}(0.36 \mathrm{~nm})$ than in graphite $(0.34 \mathrm{~nm})$, suggesting the presence of some residual surface oxygen groups in rGO. The band at $43.18^{\circ}$ corresponds to the turbostratic band of disordered carbon materials [47].

The interplanar distance, $\mathrm{d}_{002}$, of the sheets in these graphene materials is calculated by applying Bragg's law. The crystal size in direction c $\left(\mathrm{D}_{002}\right)$ of these materials is calculated by applying the

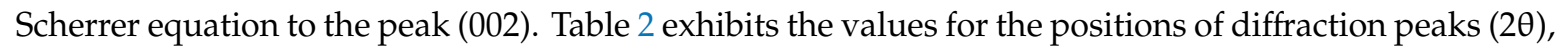
full width at half maximum (FWHM) of the peak, interplanar distance $\left(\mathrm{d}_{002}\right)$, and crystal size $\left(\mathrm{D}_{002}\right)$ for each material analyzed. The crystal size of graphite, with the lowest FWHM value, is substantially higher than that of GO or rGO. The size represents the approximate crystal width, which is related to the interplanar distance and allows the number of graphene sheets in the crystal to be calculated $\left(\mathrm{N}_{\text {sheets }}=\mathrm{D}_{002} / \mathrm{d}_{002}\right)$. Estimation of the number of sheets is much higher for graphite $(\mathrm{n}=99.3)$ than for $\mathrm{GO}(\mathrm{n}=6.4)$ or $\mathrm{rGO}(\mathrm{n}=4.0)$.

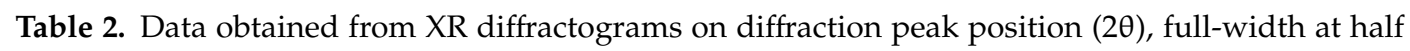
maximum (FWHM), interplanar distance $\left(\mathrm{d}_{002}\right)$, and crystal size $\left(\mathrm{D}_{002}\right)$.

\begin{tabular}{lccccc}
\hline \multicolumn{1}{c}{ Carbon } & $\mathbf{2 \theta}\left({ }^{\circ}\right)$ & $\mathbf{F W H M}\left(^{\circ}\right)$ & $\mathbf{D}_{\mathbf{0 0 2}}(\mathbf{n m})$ & $\mathbf{d}_{\mathbf{0 0 2}}(\mathbf{n m})$ & $\mathbf{N}_{\text {sheets }}$ \\
\hline Graphite & 26.56 & 0.24 & 33.3 & 0.34 & 99.3 \\
GO & 10.78 & 1.53 & 5.2 & 0.82 & 6.4 \\
rGO & 24.65 & 5.63 & 1.4 & 0.36 & 4.0 \\
\hline
\end{tabular}

Figure 3 depicts the $\mathrm{X}$-ray diffractograms of synthesized $\mathrm{TiO}_{2}$ nanoparticles and of $\mathrm{rGO}-\mathrm{TiO}_{2}$ composites with different percentages of rGO. Table 3 exhibits the $2 \theta$, FWHM, and $\mathrm{D}_{101}$ values for each material. The experimental XRD pattern for $\mathrm{TiO}_{2}$ matches JCPDS file $\mathrm{n}^{\circ} 21-1272$, and the peaks of $2 \theta$ at $25.26^{\circ}$ and $47.95^{\circ}$ confirm its anatase structure. Diffractograms of the samples show no peak assigned to rutile $\left(2 \theta=27.36^{\circ}\right.$ and $\left.36.02^{\circ}\right)$, indicating formation of the pure anatase phase of $\mathrm{TiO}_{2}$.

We observed no peaks of rGO in any $\mathrm{rGO}^{-\mathrm{TiO}_{2}}$ samples (Figure 3), possibly due to their low percentages of $\mathrm{rGO}$, so that they are masked by the diffraction signal for $\mathrm{TiO}_{2}$, and/or to destruction of the regular stack of $\mathrm{GO}$ through the intercalation of $\mathrm{TiO}_{2}$ during sample preparation $[38,39,41,43,44,48,49]$. In comparison to $\mathrm{GO}$ (Figure 2), the complete disappearance of the peak at $10.78^{\circ}$ in all composites suggests the successful conversion of GO to rGO in the final composites $[39,50]$. 


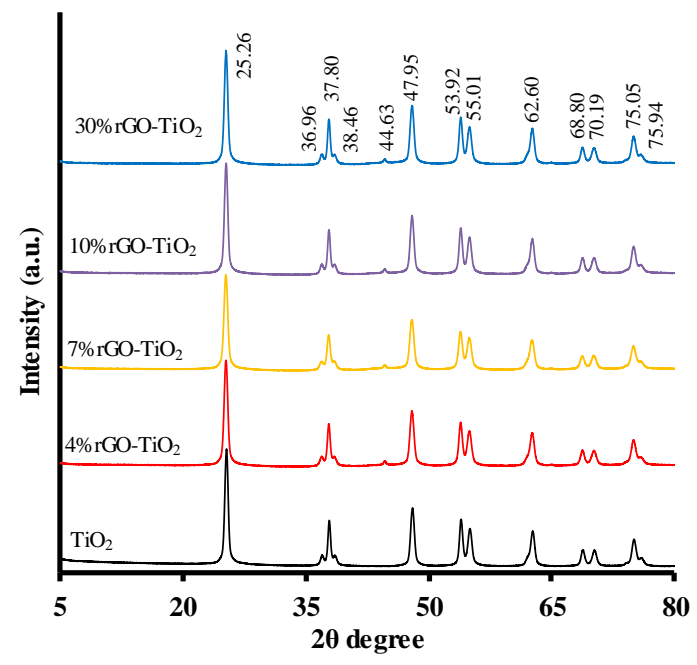

Figure 3. XRD patterns for $\mathrm{rGO}-\mathrm{TiO}_{2}$ composites.

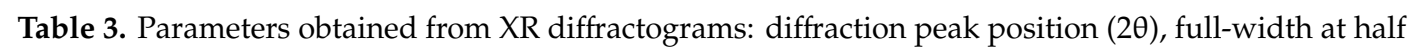
maximum (FWHM), and crystal size $\left(\mathrm{D}_{101}\right)$.

\begin{tabular}{lccc}
\hline \multicolumn{1}{r}{ Composite } & $\mathbf{2 \theta}\left(\boldsymbol{(}^{\circ}\right)$ & FWHM $\left(^{\circ}\right)$ & $\mathbf{D}_{\mathbf{1 0 1}}(\mathbf{n m})$ \\
\hline $\mathrm{TiO}_{2}$ & 25.29 & 0.409 & 19.9 \\
$4 \% \mathrm{rGO}-\mathrm{TiO}_{2}$ & 25.23 & 0.444 & 18.3 \\
$7 \% \mathrm{rGO}-\mathrm{TiO}_{2}$ & 25.22 & 0.464 & 17.6 \\
$10 \% \mathrm{rGO}-\mathrm{TiO}_{2}$ & 25.24 & 0.426 & 19.1 \\
$30 \% \mathrm{rGO}-\mathrm{TiO}_{2}$ & 25.25 & 0.414 & 19.7 \\
\hline
\end{tabular}

The peak at $25.2^{\circ}$ is slightly wider in composites than in $\mathrm{TiO}_{2}$, suggesting that the reticular structure of $\mathrm{TiO}_{2}$ is distorted by interaction with GO. The mean crystal size, calculated using the Scherrer equation for composites, is within the range of 19.7-17.6 nm, smaller than the size for $\mathrm{TiO}_{2}$ (Table 3). The smallest size is for the $7 \%$ rGO-TiO 2 composite.

Figure S2 (Supplementary Material) depicts X-ray diffractograms of P25 nanoparticles and of rGO-P25 composite materials with different percentages of rGO. Table S1 lists some of the characteristics of these materials according to their diffractograms. Peaks at $2 \theta=25.26^{\circ}$ and $48.01^{\circ}$ confirm the anatase structure. The diffractogram shows a peak at $2 \theta=27.39^{\circ}$, assigned to rutile (JCPDS $n^{\circ} 88-1175$ ) [49]. The anatase and rutile content of P25 was calculated using Equation:

$$
\mathrm{X}_{\mathrm{A}}=100 /\left(1+1.265 \mathrm{I}_{\mathrm{R}} / \mathrm{I}_{\mathrm{A}}\right)
$$

where $X_{A}$ is the fraction in anatase weight of the mixture, and $I_{A}$ and $I_{R}$ are the intensities of the diffraction peaks of anatase (101) and rutile (110) [51]. The XRD data indicate that the anatase:rutile ratio is $86: 14$. The crystal size is $20.6 \mathrm{~nm}$ for anatase and $19.3 \mathrm{~nm}$ for rutile. In composites with P25, the crystal size is changed by the presence of $\mathrm{rGO}$ (Table S1) [52]. The $\mathrm{TiO}_{2}$ sample prepared for this study contains $100 \%$ anatase. The anatase crystal size is larger in P25 $(20.6 \mathrm{~nm})$, the sample containing rutile, than in the $\mathrm{TiO}_{2}$ sample $(19.9 \mathrm{~nm})$.

\subsection{Fourier-Transform Infrared (FTIR) Spectroscopy}

Infrared spectroscopy provides information on chemical composites and their structures through the molecular vibrations associated with each band. Figure 4 depicts the FTIR spectra for GO and rGO. Graphite shows no significant peaks (spectrum not shown). GO shows numerous peaks or bands of oxygenated groups [42]. 
There is a wide band at $3420 \mathrm{~cm}^{-1}$, corresponding to stretching vibrations of the -OH bond in $\mathrm{C}-\mathrm{OH}$ groups, with possible contributions from carboxylic acids and water [25,53-56]. The small peaks at 2918 and $2846 \mathrm{~cm}^{-1}$ are attributed to stretching vibrations of $\mathrm{CH}_{2}$. The peak at $1715 \mathrm{~cm}$ corresponds to the stretching of carbonyl/carboxyl groups $(\mathrm{C}=\mathrm{O})$ of the carboxylic functionalities $(-\mathrm{COOH})$ presumably located at the sheet edges $[25,53,55-58]$. The peak at $1625 \mathrm{~cm}^{-1}$ is related to stretching in the $\mathrm{sp}^{2}$ vibration plane of $\mathrm{C}=\mathrm{C}$ bond $[55,56]$. The peak at $1372 \mathrm{~cm}^{-1}$ corresponds to bending vibrations of $\mathrm{C}-\mathrm{OH}$ hydroxyl groups [25,53,57], and the peak at $1220 \mathrm{~cm}^{-1}$ to bending vibrations of epoxy groups (C-O-C) $[25,53,56,57]$. The peak at $1030 \mathrm{~cm}^{-1}$ corresponds to the $\mathrm{C}-\mathrm{O}$ vibration of epoxy, ether, or peroxide groups [53,57]. The results obtained for GO by this technique are highly useful and complement XPS results, because it detects the presence/absence of epoxy groups, which are not differentiated from carbonyls with XPS. All the above peaks are characteristic of GO; however, in the case of rGO, the peaks at 1715, 1372, and $1030 \mathrm{~cm}^{-1}$ (attributed to vibrations of $\mathrm{COOH}$, $\mathrm{C}-\mathrm{OH}$, and $\mathrm{C}-\mathrm{O}$ groups, respectively) decrease in intensity due to the decomposition of these groups during hydrothermal treatment.

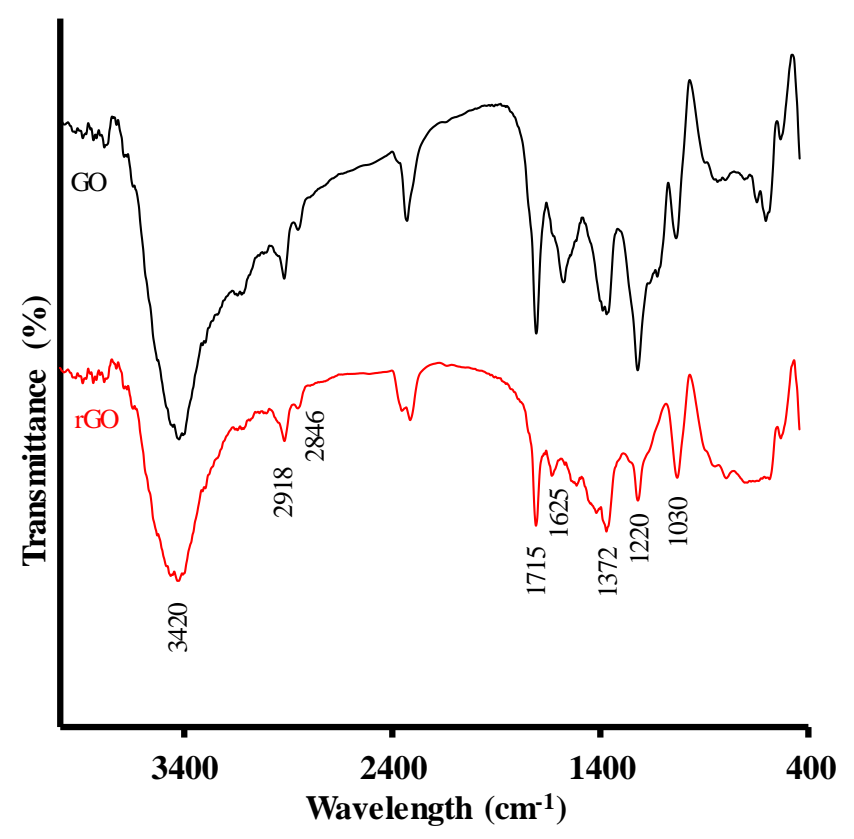

Figure 4. FTIR spectra of GO and rGO.

Figure 5 displays the IR spectra of $\mathrm{rGO}-\mathrm{TiO}_{2}$ composites. In $\mathrm{TiO}_{2}$, the strong and wide band at $3400 \mathrm{~cm}^{-1}$ corresponds to stretching vibration of hydrogen bound to surface water molecules and hydroxyl groups. This is confirmed by the presence of a peak at $1625 \mathrm{~cm}^{-1}$ caused by bending vibration of coordinated water and $\mathrm{Ti}-\mathrm{OH}$ groups $[57,59]$. This peak is also assigned to vibration of the aromatic ring in the GO structure within the composites. The reduced intensity of the peak in the composites at $1720 \mathrm{~cm}^{-1}$ suggests that they largely contain hydroxyl groups rather than ketone or carboxylic groups [58]. The reduction in the peak at $1030 \mathrm{~cm}^{-1}$ corresponds to oxygenated functional groups such as $\mathrm{C}-\mathrm{O}$ [42].

The spectra of $\mathrm{TiO}_{2}$ and composites show peaks at 650 and $519 \mathrm{~cm}^{-1}$, attributed to vibration of Ti-O-Ti bonds in $\mathrm{TiO}_{2}[25,42,57,59]$. Generally, broadbands or peaks below $1000 \mathrm{~cm}^{-1}$ in composites indicate a combination of Ti-O-Ti and Ti-O-C vibrations due to the chemical interaction of $\mathrm{TiO}_{2}$ with rGO [54]. The presence of Ti-O-C bonds indicates that GO, with residual carboxyl groups, strongly interacts with the surface hydroxyl groups of $\mathrm{TiO}_{2}$ nanoparticles and forms chemical bonds in the composites during hydrothermal treatment. 


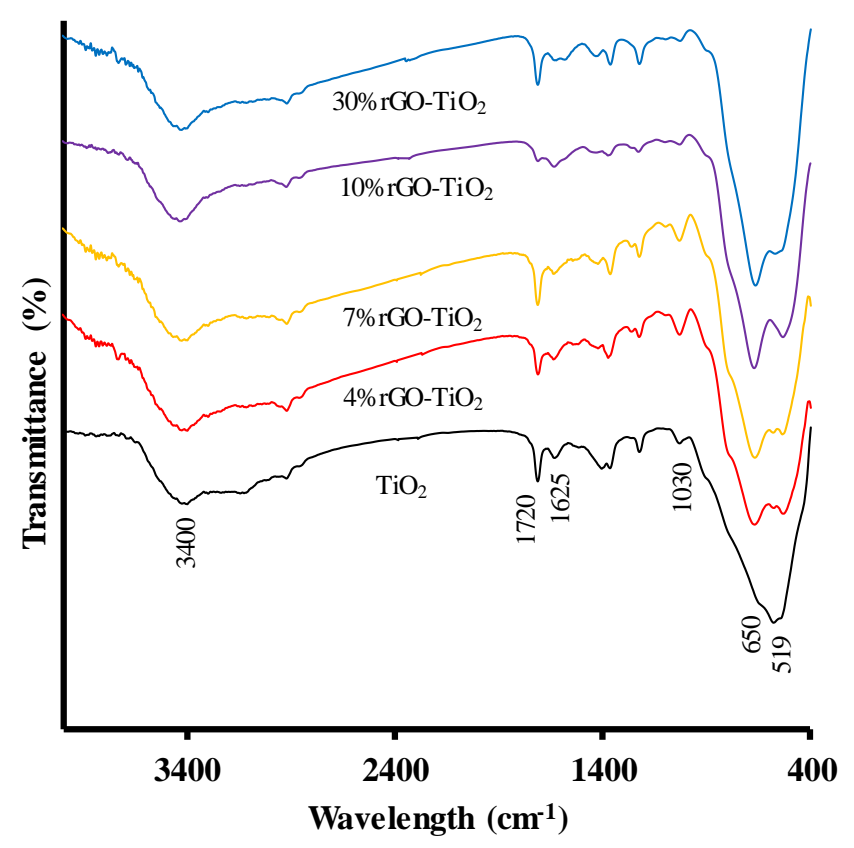

Figure 5. FTIR spectra of $\mathrm{TiO}_{2}$ and $\mathrm{rGO}-\mathrm{TiO}_{2}$ composites.

The absorption peaks of oxygenated functional groups such as $\mathrm{C}=\mathrm{O}\left(1717 \mathrm{~cm}^{-1}\right),-\mathrm{OH}\left(1170 \mathrm{~cm}^{-1}\right)$, and $\mathrm{C}-\mathrm{O}-\mathrm{C}\left(1035 \mathrm{~cm}^{-1}\right)$ drastically decrease or even disappear in composites, indicating that $\mathrm{TiO}_{2}$ preferentially binds to rGO at these sites $[25,42,55-57,60]$.

Figure S3 depicts the IR spectra of rGO-P25 composites, showing a reduced intensity of the peaks for surface groups present in rGO (Figure 4) due to the formation of bonds between P25 and rGO. Sample P25 has a wide peak at $3400 \mathrm{~cm}^{-1}$ and another at $1630 \mathrm{~cm}^{-1}$, corresponding to $\mathrm{OH}$ groups, and a wide band below $900 \mathrm{~cm}^{-1}$, attributed to the vibration of Ti-O-Ti bonds.

\subsection{Analysis of Raman Spectroscopy}

Raman spectroscopy is a powerful and non-destructive technique for characterizing the electronic and structural properties of carbon materials. In graphitic materials, the $G$ band, at $\sim 1575 \mathrm{~cm}^{-1}$, represents the perfect graphitic structure of carbon atom bonds with $\mathrm{sp}^{2}$ hybridization and is assigned to $\mathrm{E}_{2 \mathrm{~g}}$-symmetry phonons of carbon atoms with $\mathrm{sp}^{2}$ hybridization [58]. The D band, at $1354 \mathrm{~cm}^{-1}$, is assigned to the $\mathrm{K}$ point of $\mathrm{A}_{1 \mathrm{~g}}$-symmetry phonons and attributed to the presence of defects or disordered carbon. The $\mathrm{G}^{\prime}$ or $2 \mathrm{D}$ band, at $2700 \mathrm{~cm}^{-1}$, is assigned to the first overtone of band $\mathrm{D}$. This band is not caused by defects, given that it is observed in defect-free graphitic crystals [61], but rather by other characteristics of graphitic materials. The material is highly crystalline when this band is well defined and narrow. The presence of this well-defined sign further indicates the degree of graphitization of the material. Its loss of intensity and widening are associated with increased structural disorder [61].

Figure 6 and Table 4 exhibit the Raman spectra of graphite, GO, and rGO, and the parameters obtained from their analysis. The Raman spectrum of graphite shows a highly ordered structure (high crystallinity), with well-defined peaks at $1354 \mathrm{~cm}^{-1}$ (D), $1582 \mathrm{~cm}^{-1}(\mathrm{G})$, and $2714 \mathrm{~cm}^{-1}$ (2D), indicating a stacked lamina structure. 


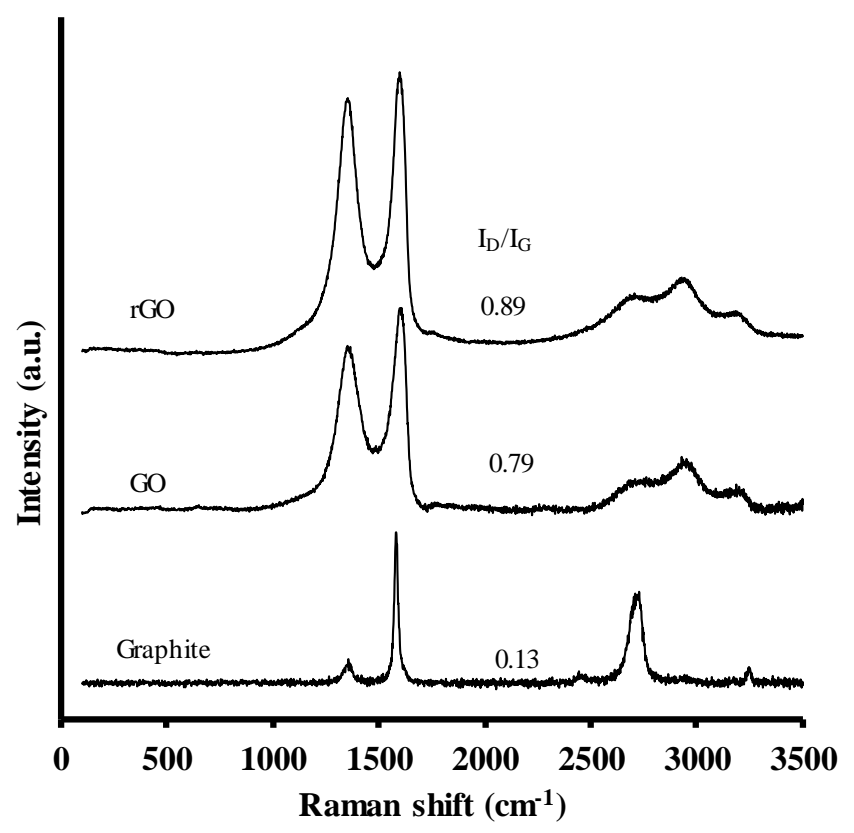

Figure 6. Raman spectra of graphite, GO, and rGO.

Table 4. Parameters obtained from Raman spectra.

\begin{tabular}{lcccc}
\hline Carbon & Banda $\mathbf{D}\left(\mathbf{c m}^{-\mathbf{1})}\right.$ & Banda G $\left(\mathbf{c m}^{-\mathbf{1})}\right.$ & $\mathbf{I}_{\mathbf{D}} / \mathbf{I}_{\mathbf{G}}$ & $\begin{array}{c}\mathbf{L}_{\mathbf{a}} \\
(\mathbf{n m})\end{array}$ \\
\hline Graphite & 1354 & 1582 & 0.13 & 134.0 \\
GO & 1359 & 1600 & 0.79 & 21.2 \\
rGO & 1353 & 1595 & 0.89 & 18.8 \\
\hline
\end{tabular}

After oxidation treatment, the Raman spectrum of graphite evidence structure modification, observing bands at $1359 \mathrm{~cm}^{-1}$ (D), $1600 \mathrm{~cm}^{-1}$ (G), $2715 \mathrm{~cm}^{-1}$ (2D), $2942 \mathrm{~cm}^{-1}\left(\mathrm{D}+\mathrm{D}^{\prime}\right)$, and $3156 \mathrm{~cm}^{-1}$ $\left(\mathrm{D}^{\prime}\right)$. The widths of $\mathrm{D}$ and $\mathrm{G}$ peaks are substantially greater than in the original graphite, indicating a lower signal and therefore lower crystallinity. In the Raman spectrum of GO, the $G$ band is wider and shifted to higher frequencies in comparison to graphite $\left(1582 \mathrm{~cm}^{-1}\right)$, while a substantial increase in the $\mathrm{D}$ band is observed. These changes in the width and intensity of $\mathrm{D}$ and $\mathrm{G}$ peaks indicate an increase in the disorder of the graphitic sheets that form the original material. This disorder derives from the creation of defects through the incorporation of oxygenated functional groups in the basal layer or through a larger increase in the proportion of oxygenated margins [62]. The increase in the $\mathrm{D}$ band can be produced by: (i) an increase in the amount of disordered carbon atoms in GO, corresponding to $\mathrm{sp}^{3}$ domains; or (ii) a significant reduction in the size of $\mathrm{sp}^{2}$ domains in the layer through ultrasonic oxidation and exfoliation. This suggests the coexistence of $\mathrm{sp}^{2}$ and $\mathrm{sp}^{3}$ hybridization; i.e., GO contains crystalline and amorphous forms of carbon [63].

The presence of the $\mathrm{D}$ peak is mainly due to a chemical functionalization that affects numerous $\mathrm{sp}^{3}$ carbon atoms in GOs, but it is attributable to defects in carbon structures in rGOs and varies according to the density of defects and the distance between them. The removal of surface functional groups by the reduction process produces vacancies and the reorganization of atoms in the carbon structure (rings with five or seven members), among other defects.

The shift of the $G$ peak to lower frequencies when passing from GO to rGO is due to the partial elimination of oxygenated groups. Results from GO and rGO samples indicate that oxidation was effective and that oxygenated groups have not been completely eliminated in the rGO sample.

The ratio of $\mathrm{D}$ band to $\mathrm{G}$ band intensities $\left(\mathrm{I}_{\mathrm{D}} / \mathrm{I}_{\mathrm{G}}\right)$ gives the proportion of amorphous and disordered carbon $\left(\mathrm{sp}^{3}\right)$ with respect to graphitic carbon $\left(\mathrm{sp}^{2}\right)$, allowing comparison of the structural order among 
the samples. In this way, the $\mathrm{I}_{\mathrm{D}} / \mathrm{I}_{\mathrm{G}}$ ratio is 0.13 for graphite, 0.79 for $\mathrm{GO}$, and 0.89 for $\mathrm{rGO}$. The higher $\mathrm{I}_{\mathrm{D}} / \mathrm{I}_{\mathrm{G}}$ in GO results from the greater disorder of this structure, due to oxygenated functional groups produced during oxygenation of the graphite. The oxidation process endows the graphite layers and their fragmentation with a certain amorphous character. The ends of the fragments act as defects, thereby increasing the intensity of band $\mathrm{D}$. These results are in agreement with previous reports $[38,45]$. The higher $\mathrm{I}_{\mathrm{D}} / \mathrm{I}_{\mathrm{G}}$ ratio for $\mathrm{rGO}$ than for GO suggests a reduction in the mean size of $\mathrm{sp}^{2}$ domains after the reduction of exfoliated GO due to the elimination of oxygenated functional groups by the hydrothermal treatment. It is reasonable to consider that GO reduction causes fragmentation throughout reactive sites, producing new graphitic domains as well as large amounts of edges that act as defects, increasing the D peak [45].

The ratio between intensities is also frequently used to determine the crystal size parallel to basal planes, $L_{a}$, using the equation of Tuinstra and Koenig (Equation (2)) [63-65]:

$$
L_{a}(n m)=\left(2.4 \times 10^{-10}\right) \lambda_{l}^{4}\left(\frac{I_{D}}{I_{G}}\right)^{-1}
$$

where $\lambda_{l}$ is the laser excitation wavelength $(514.5 \mathrm{~nm})$.

$L_{a}$ values are $134 \mathrm{~nm}$ for graphite, $21.2 \mathrm{~nm}$ for GO, and $18.8 \mathrm{~nm}$ for rGO (Table 4), within the range described in the literature [66]. A higher $L_{a}$ value indicates an increased $\mathrm{sp}^{2}$ domain in the carbonous network.

Figure 7 and Table 5 display the Raman spectra of the synthetized composites and the parameters obtained from them. Differences are observed between rGO composites and GO (Table 4), including a systematic variation in the position/intensity of $\mathrm{D}$ and $2 \mathrm{D}$ bands, indicating its reduction. In general, their position shifts to lower wavelengths (13.7 for $\mathrm{D}$ band and $35.3 \mathrm{~cm}^{-1}$ for $2 \mathrm{D}$ band) and their intensity increases. These variations in $\mathrm{D}$ and $2 \mathrm{D}$ bands in the composites can largely be attributed to the anchoring of $\mathrm{TiO}_{2}$ nanoparticles, which act as defects on the surface of rGO sheets and preserve their structural integrity after the deposition of $\mathrm{TiO}_{2}$. Therefore, the presence of these two peaks suggests that the structure of rGO persists within the composite [48]. In addition, the $\mathrm{I}_{\mathrm{D}} / \mathrm{I}_{\mathrm{G}}$ ratios in the composites (0.95-0.98) are higher than in the rGO sample (0.89), suggesting a structural disorder related to a strong interaction between $\mathrm{TiO}_{2}$ nanoparticles and rGO sheets after reduction during hydrothermal treatment [48]. It can therefore be concluded that the composites are formed by graphene nanosheets coated with $\mathrm{TiO}_{2}$ nanoparticles.

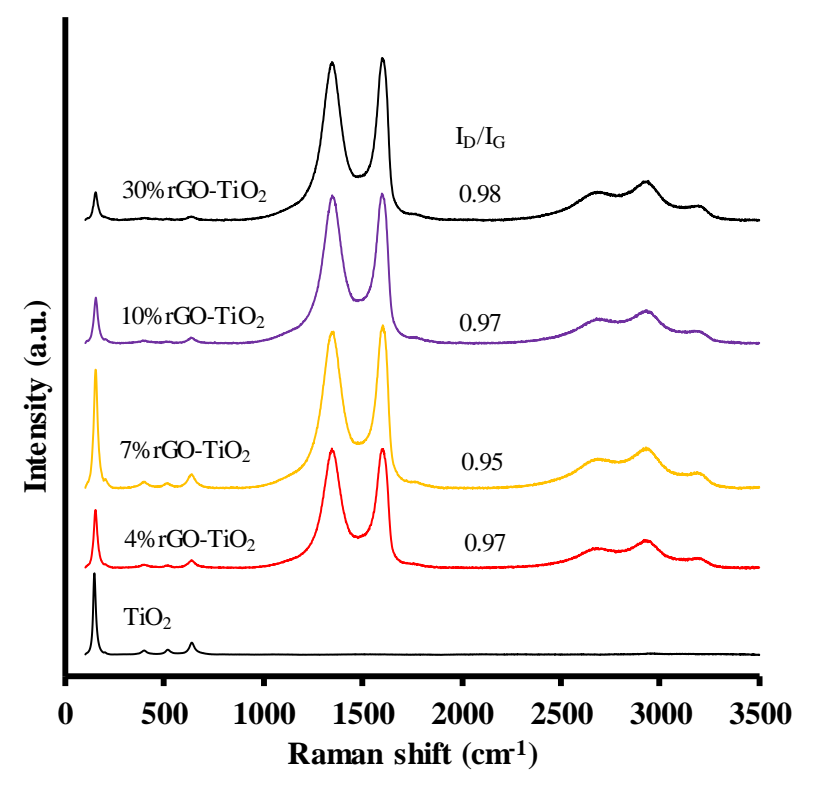

Figure 7. Raman spectra of $\mathrm{TiO}_{2}$ and $x \mathrm{rGO}-\mathrm{TiO}_{2}$ composites. 
Table 5. Parameters obtained from Raman spectra for $\mathrm{TiO}_{2}$ and $\mathrm{xrGO}-\mathrm{TiO}_{2}$ composites.

\begin{tabular}{|c|c|c|c|c|c|c|}
\hline Sample & $\begin{array}{c}\text { Mode } E_{g} \\
\left(\mathrm{~cm}^{-1}\right)\end{array}$ & $\begin{array}{c}\text { Banda D } \\
\left(\mathrm{cm}^{-1}\right)\end{array}$ & $\begin{array}{c}\text { Banda G } \\
\left(\mathrm{cm}^{-1}\right)\end{array}$ & $\mathbf{I}_{\mathrm{D}} / \mathbf{I}_{\mathrm{G}}$ & $\begin{array}{c}\mathrm{L}_{\mathrm{a}} \\
(\mathrm{nm})\end{array}$ & $\mathbf{I}_{\mathrm{D}} / \mathrm{I}_{\mathrm{Eg}}$ \\
\hline $\mathrm{TiO}_{2}$ & 146 & - & - & & & \\
\hline $4 \% \mathrm{rGO}-\mathrm{TiO}_{2}$ & 151 & 1346 & 1597 & 0.97 & 17.3 & 2.03 \\
\hline $7 \%$ rGO-TiO 2 & 152 & 1346 & 1597 & 0.95 & 17.7 & 1.33 \\
\hline $10 \% \mathrm{rGO}^{-\mathrm{TiO}_{2}}$ & 153 & 1347 & 1596 & 0.97 & 17.4 & 3.25 \\
\hline $30 \%$ rGO-TiO 2 & 153 & 1345 & 1597 & 0.98 & 17.2 & 5.81 \\
\hline
\end{tabular}

The increase in $\mathrm{I}_{\mathrm{D}} / \mathrm{I}_{\mathrm{G}}$ ratio intensities from GO, $\mathrm{rGO}$, to $\mathrm{rGO}-\mathrm{TiO}_{2}$ indicates a decrease in the mean number of $\mathrm{sp}^{2}$ domains formed during the hydrothermal reaction. The increased $\mathrm{I}_{\mathrm{D}} / \mathrm{I}_{\mathrm{G}}$ ratio in composite spectra also confirms the formation of $\mathrm{rGO}^{-\mathrm{TiO}_{2}}$ composites by the hydrothermal treatment $[39,67,68]$. The $\mathrm{I}_{\mathrm{D}} / \mathrm{I}_{\mathrm{G}}$ ratio is $20-24 \%$ higher in the composites than in $\mathrm{GO}$, and the smallest increase is in the $7 \%$ rGO- $\mathrm{TiO}_{2}$ sample.

$\mathrm{TiO}_{2}$ nanoparticles were identified in all composites by the appearance of bands at lower frequencies $\left(100-700 \mathrm{~cm}^{-1}\right)$. Raman active modes, $\mathrm{A}_{1 \mathrm{~g}}+2 \mathrm{~B}_{1 \mathrm{~g}}+3 \mathrm{E}_{\mathrm{g}}$, are detected at $146 \mathrm{~cm}^{-1}\left(\mathrm{E}_{\mathrm{g}}\right)$, $197 \mathrm{~cm}^{-1}\left(\mathrm{E}_{\mathrm{g}}\right), 397 \mathrm{~cm}^{-1}\left(\mathrm{~B}_{1 \mathrm{~g}}\right), 517 \mathrm{~cm}^{-1}\left(\mathrm{~A}_{1 \mathrm{~g}}\right)$, and $638 \mathrm{~cm}^{-1}\left(\mathrm{E}_{\mathrm{g}}\right)$, indicating the presence of the anatase phase in all samples $[50,69]$. No peaks are observed corresponding to the rutile-to-brookite phase, in agreement with the XRD results [48].

The peaks at 144,197 , and $639 \mathrm{~cm}^{-1}$ correspond to the $\mathrm{E}_{\mathrm{g}}$ mode of the symmetric valence vibration of the O-Ti bond; while the signal at $396 \mathrm{~cm}^{-1}$ corresponds to the $\mathrm{B}_{1 \mathrm{~g}}$ mode of the symmetric bending vibration $\mathrm{O}-\mathrm{Ti}-\mathrm{O}$ and the signal at $517 \mathrm{~cm}^{-1}$ to the $\mathrm{A}_{1 \mathrm{~g}}$ mode of the asymmetric vibration of the O-Ti bond [70].

In the composites, the band at $146 \mathrm{~cm}^{-1}$ shifts to a higher wavelength, from 146 to $153 \mathrm{~cm}^{-1}$, and widens (FHWM rises from 15 to $25 \mathrm{~cm}^{-1}$ ) through the interaction of $\mathrm{TiO}_{2}$ metallic ions with GO sheets $[50,71]$ and can be attributed to the formation of Ti-O-C on the surface of composites.

Figure S4 and Table S2 exhibit the Raman spectra of rGO-P25 composites and the parameters obtained. The presence of bands at frequencies below $700 \mathrm{~cm}^{-1}$ indicates the presence of P25 nanoparticles. The $\mathrm{I}_{\mathrm{D}} / \mathrm{I}_{\mathrm{G}}$ ratio is similar to that for $\mathrm{rGO}$, and La values are higher than in $\mathrm{rGO}-\mathrm{TiO}_{2}$ composites (Table 5).

\subsection{X-ray Photoelectron Spectroscopy Analysis}

GO-based samples were characterized by XPS to identify functional groups. Figure 8 depicts the XPS spectra of $\mathrm{C} 1 \mathrm{~s}$ and $\mathrm{O} 1 \mathrm{~s}$ regions of $\mathrm{GO}$ and $\mathrm{rGO}$ samples. Table 6 lists the bond energies (BE) values, $\mathrm{C} / \mathrm{O}$ ratios, and percentages of the corresponding deconvoluted peaks of $\mathrm{C}$ and $\mathrm{O}$.

The $\mathrm{C}$ 1s spectrum of GO deconvolutes into four peaks corresponding to four types of carbon bond. $\mathrm{BE}$ at $284.6 \mathrm{eV}$ is attributed to $\mathrm{C}=\mathrm{C} \mathrm{sp}{ }^{2}$ bonds and $\mathrm{BE}$ at $285.5 \mathrm{eV}$ to $\mathrm{C}-\mathrm{C} \mathrm{sp}{ }^{3}$ bonds. $\mathrm{BE}$ at 286.5 is assigned to $\mathrm{C}-\mathrm{O}$ bonds, including epoxy and hydroxyl groups, and the peak at $288.5 \mathrm{eV}$ is attributed to $\mathrm{C}=\mathrm{O}$, corresponding to carbonyl and carboxyl groups [72]. The oxygen content of the GO sample is $23.3 \%$, with a $\mathrm{C} / \mathrm{O}$ ratio of 3.3 , similar to previously reported values [72,73]. The main oxygenated species correspond to epoxy and hydroxyl groups in basal layers (13.8\%) versus carbonyl and carboxyl groups on the edges $(8.1 \%)$, as observed in Table 6.

The spectrum of $\mathrm{O} 1 \mathrm{~s}$ of GO deconvolutes into four peaks at BEs of 531.2, 532.5, 533.7, and $534.4 \mathrm{eV}$, corresponding to $\mathrm{C}=\mathrm{O}$ bonds in carbonyl or carboxyl groups, $\mathrm{C}-\mathrm{O}$ a bonds in alcohol, ether and epoxy groups, $\mathrm{C}-\mathrm{Ob}$ bonds in carboxyl and ester groups, and peroxyacid or peroxyester groups, respectively.

Oxygenated species decrease in the rGO sample, as observed in the species percentages in $C 1 \mathrm{~s}$ (Table 6). The percentage of hydroxyl and epoxy groups $(286.6 \mathrm{eV})$ is $42 \%$ lower than in the GO sample. $\mathrm{C}=\mathrm{O}$ groups at $288.4 \mathrm{eV}$ is also decreased, but by a lower percentage. These findings indicate that oxygenated groups on the edges are less easily removed during reduction than are those on basal 
layers. Reduction increases the percentage of $C=C$ bonds $(284.6 \mathrm{eV})$, indicating the restoration of the graphitic structure after the reduction process [72,74].
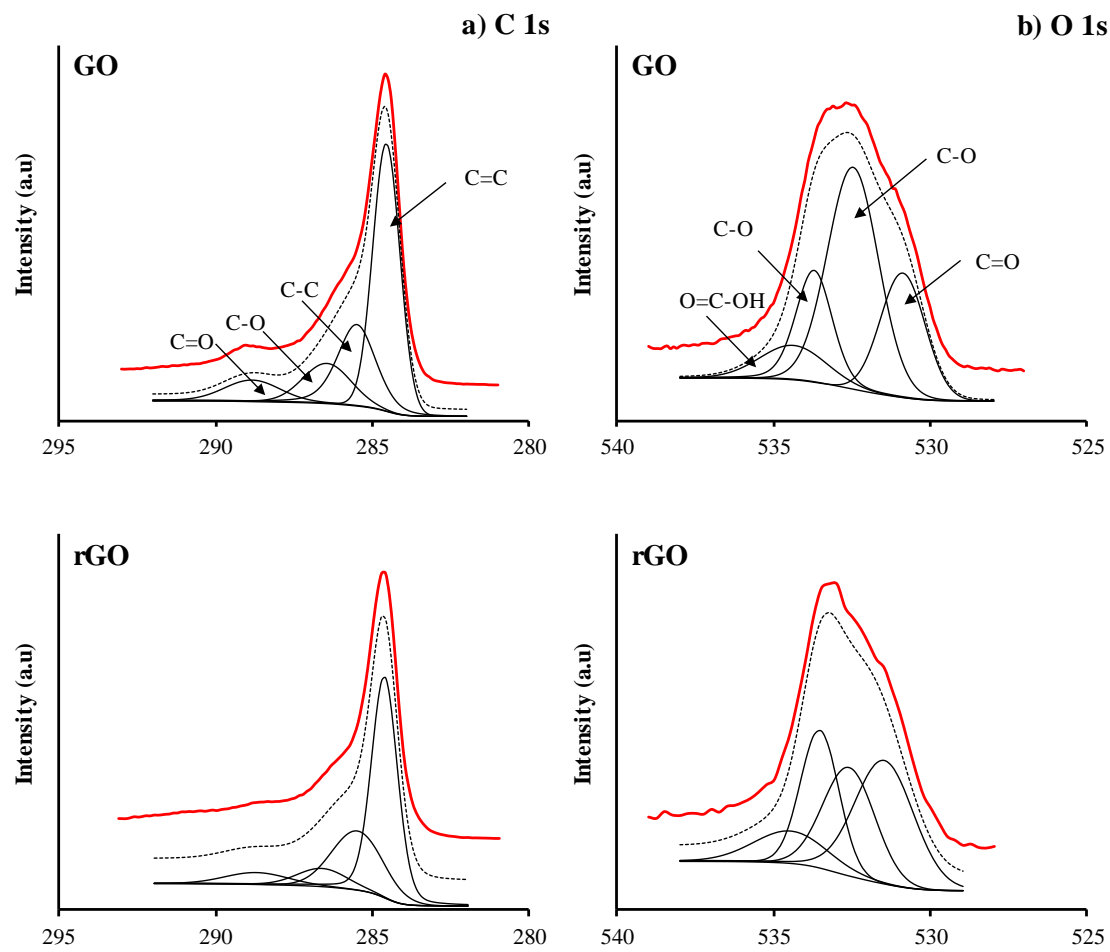

Figure 8. XPS profiles of GO and rGO: (a) C 1s spectra and (b) O 1s spectra. Continuous red line: experimental profile; discontinuous black line: fitted profile.

Table 6. C/O ratio, species percentages, bond energies (in brackets, eV), and oxygen content obtained by XPS analysis.

\begin{tabular}{lcccccc}
\hline Sample & C/O & O (\%) & C 1s (\%) \\
\hline GO & 3.30 & 23.3 & C=C & C-C & C-O & C=O \\
\hline rGO & 6.52 & 13.3 & $57.8(284.6)$ & $26.3(285.5)$ & $13.8(286.5)$ & $8.1(288.5)$ \\
& & O 1s (\%) & $27.6(285.5)$ & $8.0(286.6)$ & $6.7(288.4)$ \\
& & C=O & C-Oa & C-Ob & O=C-OH \\
\hline GO & & $23.1(531.2)$ & $48.6(532.5)$ & $18.8(533.7)$ & $9.6(534.4)$ \\
rGO & & $35.8(531.5)$ & $27.2(532.6)$ & $27.4(533.5)$ & $11.6(534.5)$ \\
\hline
\end{tabular}

This greater decrease at $532.6 \mathrm{eV}, \mathrm{C}-\mathrm{Oa}$, in hydroxyl and epoxy groups versus carbonyl and carboxyl groups is also observed in the XPS spectra of $\mathrm{O}$ 1s (Figure 8). Removal of oxygenated groups by the reduction process is also observed in the comparison of atomic percentages of $\mathrm{O}$ between GO and $\mathrm{rGO}$ samples, which are $23.3 \%$ and $13.3 \%$, respectively.

Figure 9 depicts the XPS spectra of $\mathrm{C} 1 \mathrm{~s}, \mathrm{O} 1 \mathrm{~s}$, and Ti $2 \mathrm{p}$ regions of $\mathrm{rGO} / \mathrm{TiO}_{2}$ composite materials and Table 7 exhibits the bond, assignation, and quantification energies of the peaks of $\mathrm{C} 1 \mathrm{~s}, \mathrm{O} 1 \mathrm{~s}$, and Ti $2 \mathrm{p}$ regions in these samples.

Figure S5 and Table S3 of Supplementary Material show the results obtained for rGO/P25 composite materials.

The Ti $2 \mathrm{p}$ spectrum of composite materials shows two centered peaks at $458.1 \mathrm{eV}$, assigned to Ti $2 \mathrm{p}_{1 / 2}$, and $463.8 \mathrm{eV}$, assigned to Ti $2 \mathrm{p}_{3 / 2}$, with a separation energy of $5.7 \mathrm{eV}$, consistent with the BE values of $\mathrm{Ti}^{4+}$ in pure anatase [75]. The $\mathrm{C} 1 \mathrm{~s}$ spectrum deconvolutes into four peaks, corresponding to $\mathrm{C}=\mathrm{C}$, C-C, C-O, and C $=\mathrm{O}$ bonds and BEs of 284.4, 285.4, 286.3, and $288.0 \mathrm{eV}$, respectively. Comparison between 
the composite materials and GO (Table 6) reveals an increased percentage of $\mathrm{C}=\mathrm{C}$ and a reduced percentage of oxygenated groups. This may be due to the nucleation and growth of $\mathrm{TiO}_{2}$ nanoparticles in $\mathrm{GO}$ sheets, where $\mathrm{C}-\mathrm{O}$ groups are consumed and partially reduced to $\mathrm{C}=\mathrm{C}[76]$.

The partial reduction of GO is confirmed by calculating the ratio of peak areas for oxidized carbon to peak areas for completely reduced carbon atoms, AC-O/AC-C. Thus, the AC-O/AC-C ratio is lower in all $\mathrm{rGO} / \mathrm{TiO}_{2}$ composite materials than in the original GO, being 0.28 for the GO sample, 0.17 for $\mathrm{rGO}, 0.18$ for $4 \% \mathrm{rGO} / \mathrm{TiO}_{2}, 0.19$ for $7 \% \mathrm{rGO} / \mathrm{TiO}_{2}, 0.21$ for $10 \% \mathrm{rGO} / \mathrm{TiO}_{2}$, and 0.23 for $30 \%$ $\mathrm{rGO} / \mathrm{TiO}_{2}$ (Table 7).

The XPS spectrum of deconvoluted $\mathrm{O} 1 \mathrm{~s}$ shows three peaks at BEs of 529.3, 530.3, and $531.3 \mathrm{eV}$, corresponding to $\mathrm{O}^{2-}$ in the $\mathrm{TiO}_{2}$ network, $\mathrm{OH}^{-}$adsorbed on the surface of $\mathrm{TiO}_{2}$, and $\mathrm{C}-\mathrm{O}$ groups, respectively [76].

The $\mathrm{Ti} / \mathrm{C}$ ratio is 0.75 for catalyst $4 \% \mathrm{rGO}-\mathrm{TiO}_{2}, 0.77$ for $7 \% \mathrm{rGO}-\mathrm{TiO}_{2}, 0.72$ for $10 \% \mathrm{rGO}-\mathrm{TiO}_{2}$, and 0.41 for $30 \% \mathrm{rGO}^{-\mathrm{TiO}_{2}}$ (Table 7). The Ti/C ratio is slightly higher in $7 \% \mathrm{rGO} / \mathrm{TiO}_{2}$ than in the other samples, suggesting that $\mathrm{TiO}_{2}$ nanoparticles permit superior dispersion of rGO sheets in the $\mathrm{TiO}_{2}$ matrix.
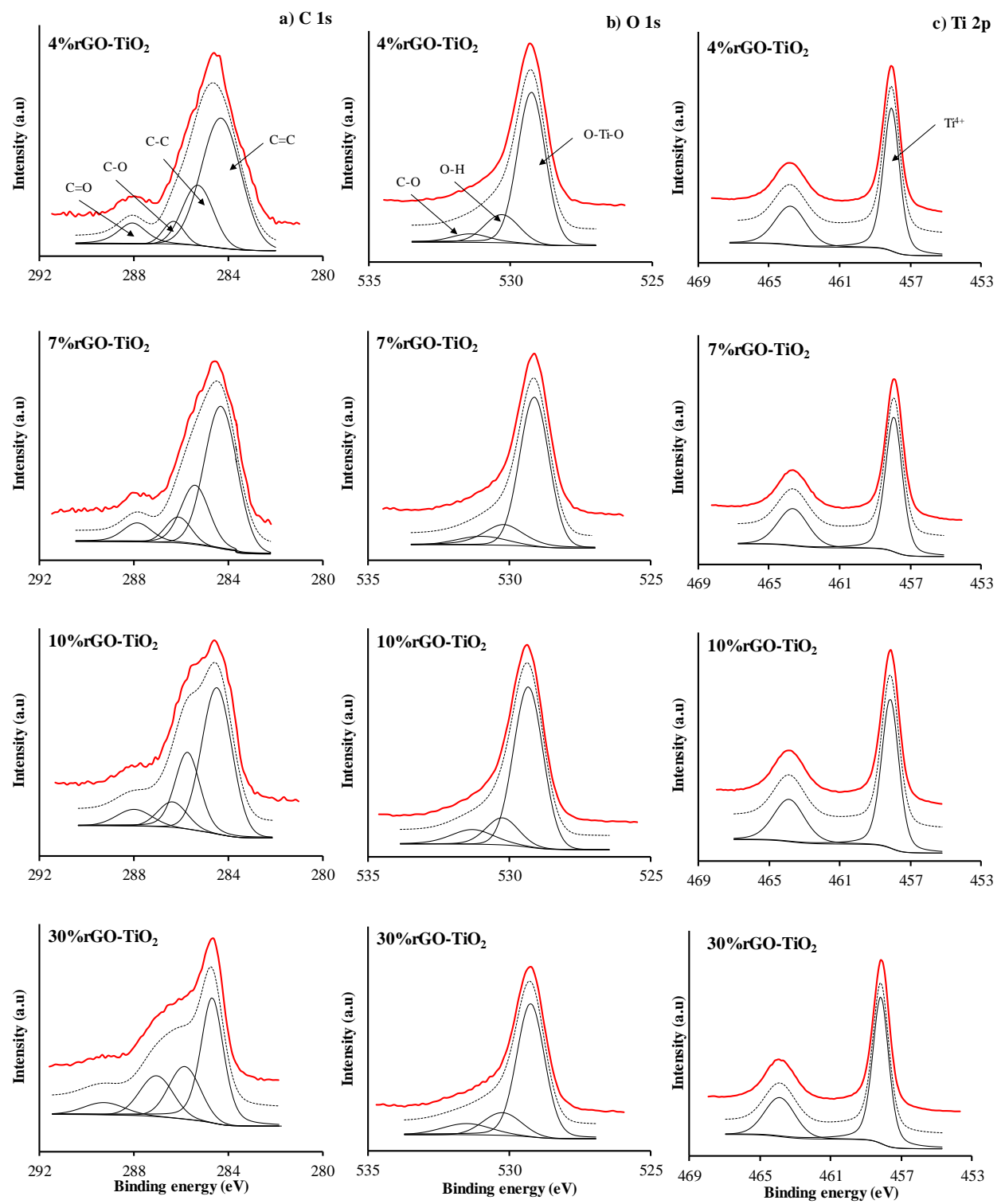

Figure 9. XPS profiles of $\mathrm{rGO}^{-\mathrm{TiO}_{2}}$ composites: (a) $\mathrm{C}$ 1s spectra; (b) $\mathrm{O}$ 1s spectra and (c) $\mathrm{Ti}$ 2p spectra. Continuous red line: experimental profile; discontinuous black line: fitted profile. 
Table 7. Ti/C, $\mathrm{A}_{\mathrm{C}-\mathrm{O}} / \mathrm{A}_{\mathrm{C}-\mathrm{C}}$ ratios, species percentages, and bond energies (in brackets, $\mathrm{eV}$ ) obtained by XPS analysis.

\begin{tabular}{|c|c|c|c|c|c|c|}
\hline Sample & $\mathrm{Ti} / \mathrm{C}$ & $\mathbf{A}_{\mathrm{C}-\mathrm{O}} / \mathbf{A}_{\mathrm{C}-\mathrm{C}}$ & C 1s (\%) & & & \\
\hline & & & $C=C$ & $\mathrm{C}-\mathrm{C}$ & $\mathrm{C}-\mathrm{O}$ & $\mathrm{C}=\mathrm{O}$ \\
\hline $4 \%$ rGO$-\mathrm{TiO}_{2}$ & 0.75 & 0.18 & $62.5(284.3)$ & $22.4(285.3)$ & $6.0(286.3)$ & $9.1(288.1)$ \\
\hline $7 \%$ rGO-TiO 2 & 0.77 & 0.19 & $60.9(284.3)$ & $23.1(285.4)$ & $8.6(286.1)$ & $7.4(287.9)$ \\
\hline $10 \%$ rGO-TiO 2 & 0.72 & 0.21 & $58.0(284.5)$ & $24.3(285.7)$ & $10.1(286.4)$ & $7.6(288.0)$ \\
\hline $30 \%$ rGO-TiO 2 & 0.41 & 0.23 & $55.5(284.7)$ & $26.0(285.9)$ & $11.3(286.7)$ & 7.1(289.3) \\
\hline
\end{tabular}

\subsection{Diffuse Reflectance UV-Vis Spectroscopy Analysis}

UV-Vis spectroscopy is an effective optical technique for characterizing the electronic structure of semiconductors. The electronic properties of the materials under study were analyzed by obtaining diffuse reflectance spectra (DRS), allowing calculation of the band gap energy $\left(E_{g}\right)$ using Kubelka-Munk transformed function (Equation (3)) [77]:

$$
(F(R) \times h v)^{1 / 2}=C\left(h v-E_{g}\right)
$$

where $\mathrm{n}$ is the constant for the type of optical transition, with values of $\mathrm{n}=2$ for permitted indirect transitions, $\mathrm{n}=3$ for forbidden indirect transitions, $\mathrm{n}=1 / 2$ for permitted direct transitions, and $\mathrm{n}=3 / 2$ for forbidden direct transitions. The $E_{g}$ value can be calculated from Equation (3), plotting $(F(R) \times h v)^{1 / n}$ against $\mathrm{h} v$, considering $\mathrm{n}=2$ for permitted indirect transitions, as suggested by other authors [78]. Figure 10 plots the transformed Kubelka-Munk function against the energy of light. The band gap energy is $3.20 \mathrm{eV}$ for $\mathrm{TiO}_{2}, 3.09 \mathrm{eV}$ for $4 \% \mathrm{rGO}-\mathrm{TiO}_{2}, 2.75 \mathrm{eV}$ for $7 \% \mathrm{rGO}-\mathrm{TiO}_{2}, 2.63 \mathrm{eV}$ for $10 \%$ $\mathrm{rGO}^{-\mathrm{TiO}_{2}}$, and $2.55 \mathrm{eV}$ for $30 \% \mathrm{rGO}^{-\mathrm{TiO}_{2}}$. These results demonstrate the influence of $\mathrm{rGO}$ on the optical characteristics of $\mathrm{TiO}_{2}$ and that an increase in percentage $\mathrm{rGO}$ narrows the band gap in composites. This phenomenon can be attributed to the formation of Ti-O-C bonds in the composites during hydrothermal treatment, similar to observations in other materials [37].

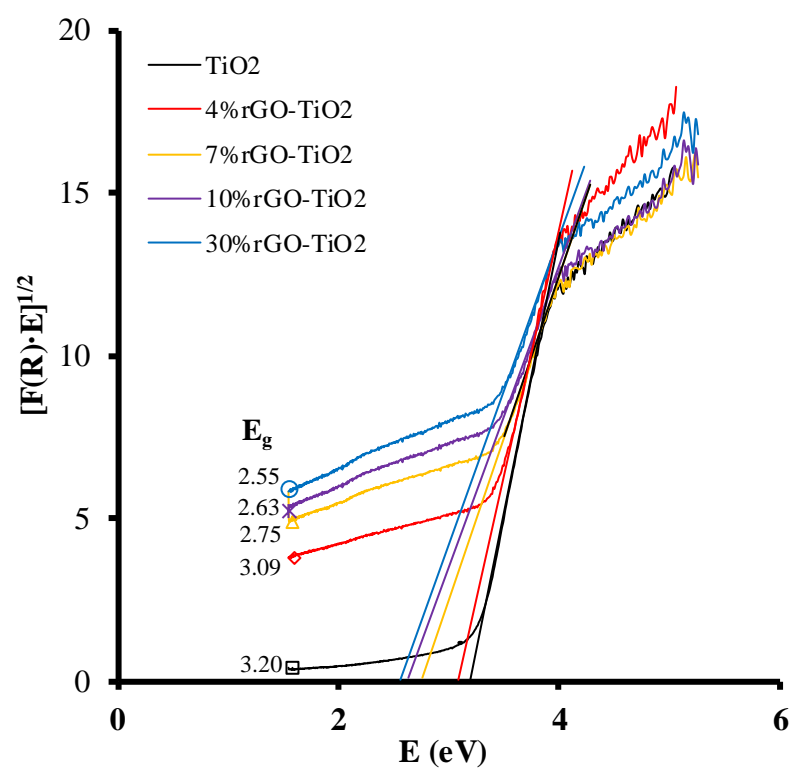

Figure 10. Relationship between transformed Kubelka-Munk function and light energy for $\mathrm{TiO}_{2}$ and rGO-TiO 2 composites. 


\subsection{Photoluminescence Analysis}

Photoluminescence is frequently used to examine the surface structure and excited status of semiconductors, as well as to analyze the recombination of their electron-hole pairs [21]. Figure 11 depicts the photoluminescence spectra of $\mathrm{TiO}_{2}$ and composite materials with different rGO percentages. The luminescence efficiency of the $\mathrm{rGO}-\mathrm{TiO}_{2}$ composites is much lower than that of the bare $\mathrm{TiO}_{2}$, indicating the depressed recombination of the electron-hole pairs in the composites [21] due to electron transfer from excited $\mathrm{TiO}_{2}$ to $\mathrm{rGO}$, hampering electron recombination $[39,60]$. The PL peak at $364 \mathrm{~nm}$ (Figure 11) is attributed to the band-to-band recombination. The band at $400-450 \mathrm{~nm}$ is attributed to the excitonic PL peaks trapped by surface states and defects, and the peak at $460 \mathrm{~nm}$ is induced by indirect recombination via oxygen defects [79].

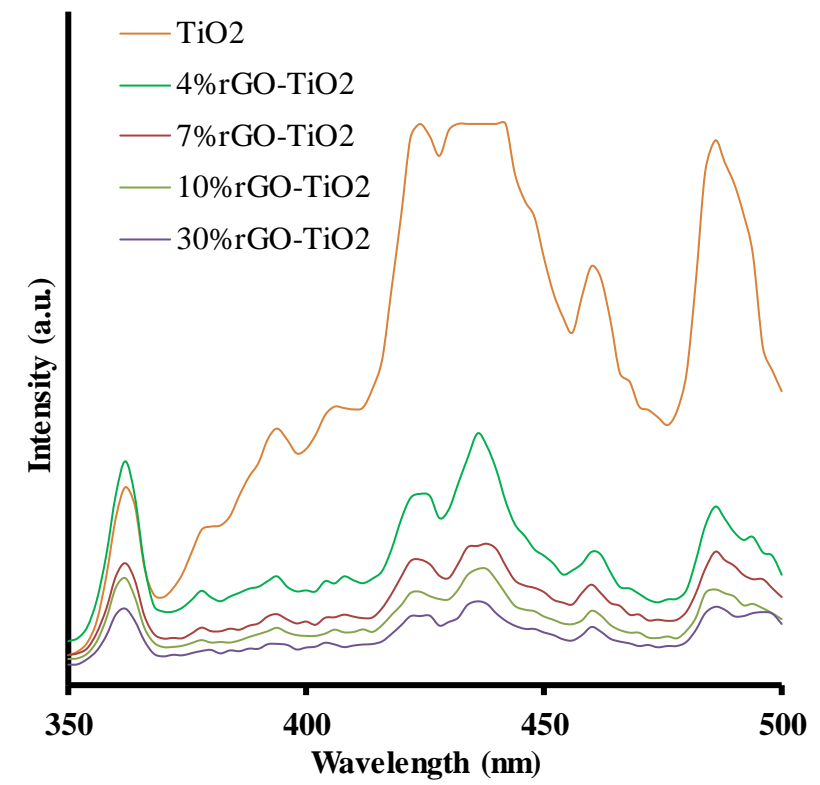

Figure 11. Photoluminescence spectra of $\mathrm{TiO}_{2}$ and $\mathrm{rGO}-\mathrm{TiO}_{2}$ composites with different $\mathrm{rGO}$ percentages (excitation wavelength $264 \mathrm{~nm}$ ).

Figure S6 in Supplementary Material shows the energy level diagram of $\mathrm{TiO}_{2}$ and rGO. $\mathrm{The}^{\mathrm{TiO}} 2$ conduction band is $-4.2 \mathrm{eV}$ and the valence band is $-7.4 \mathrm{eV}$, while $\mathrm{rGO}$ has a conduction band of $-4.4 \mathrm{eV}$. These levels allow photoinduced electrons to transfer from the $\mathrm{TiO}_{2}$ conduction band to $\mathrm{rGO}$, which can efficiently separate photoinduced electrons and, as indicated above, prevent recombination of charge carriers in photocatalytic processes.

\subsection{Photocatalytic Degradation of EtP}

Photocatalytic processes are based on the generation of superoxide and hydroxyl radicals capable of oxidizing pollutants. The following are the main reactions involved in the photocatalytic processes of oxidation of pollutants in aqueous solution and in the presence of $\mathrm{TiO}_{2}$ [80]:

$$
\begin{gathered}
\text { Photoexcitation } \mathrm{TiO}_{2}+\mathrm{hv} \rightarrow \mathrm{e}^{-}+\mathrm{h}^{+} \\
\text {Charge-carrier trapping of } \mathrm{e}^{-} \mathrm{e}^{-} \mathrm{CB} \rightarrow \mathrm{e}^{-} \mathrm{TR} \\
\text { Charge-carrier trapping of } \mathrm{h}^{+} \mathrm{h}^{+} \mathrm{VB} \rightarrow \mathrm{h}^{+} \mathrm{TR} \\
\text { Electron-hole recombination } \mathrm{e}^{-} \mathrm{TR}+\mathrm{h}^{+} \mathrm{VB}\left(\mathrm{h}^{+} \mathrm{TR}\right) \rightarrow \mathrm{e}^{-} \mathrm{CB}+\text { heat } \\
\text { Photoexcited } \mathrm{e}^{-} \text {scavenging }\left(\mathrm{O}_{2}\right)_{\text {ads }}+\mathrm{e}^{-} \rightarrow \mathrm{O}_{2}^{\bullet-}
\end{gathered}
$$




$$
\text { Oxidation to } \mathrm{HO}^{\bullet} \mathrm{H}_{2} \mathrm{O}+\mathrm{h}^{+} \rightarrow \mathrm{HO}^{\bullet}+\mathrm{H}^{+}
$$

Photodegradation by $\mathrm{HO}^{\bullet}$ Pollutants $+\mathrm{HO}^{\bullet} \rightarrow$ intermediate(s) $+\mathrm{H}_{2} \mathrm{O}$

Direct photoholes Pollutants $+\mathrm{h}^{+} \rightarrow$ intermediate(s)/degradation products

$$
\begin{gathered}
\text { Protonation of superoxide } \mathrm{O}_{2}{ }^{--}+\mathrm{H}^{+} \rightarrow \mathrm{HO}_{2}{ }^{\bullet} \\
\text { Co-scavenging of } \mathrm{e}^{-} \mathrm{HO}_{2}{ }^{\bullet}+\mathrm{e}^{-} \rightarrow \mathrm{HO}_{2}^{-} \\
\text {Formation of } \mathrm{H}_{2} \mathrm{O}_{2} \mathrm{HO}_{2}^{-}+\mathrm{H}^{+} \rightarrow \mathrm{H}_{2} \mathrm{O}_{2}
\end{gathered}
$$

The composites with different GO percentages obtained by hydrothermal treatment of synthesized $\mathrm{TiO}_{2}$ were used as catalysts in EtP photodegradation under UV radiation. Figure 12 depicts the photodegradation kinetics of EtP by UV radiation and in the presence of $\mathrm{x} \% \mathrm{rGO}-\mathrm{TiO}_{2}$ composites.

Table 8 lists the results of analyzing the photodegradation kinetics, which fit a pseudo-first order kinetic model and indicate the rate of photocatalytic degradation of EtP.

Before performing the photodegradation experiments, paraben adsorption experiments were conducted on the composites under study to eliminate the contribution of adsorption to the overall EtP removal process. In addition, the effect of direct photolysis on EtP removal was studied by using UV radiation alone, which achieves $61.5 \%$ degradation after 40 min irradiation with $14.0 \%$ TOC removal (Table 8).

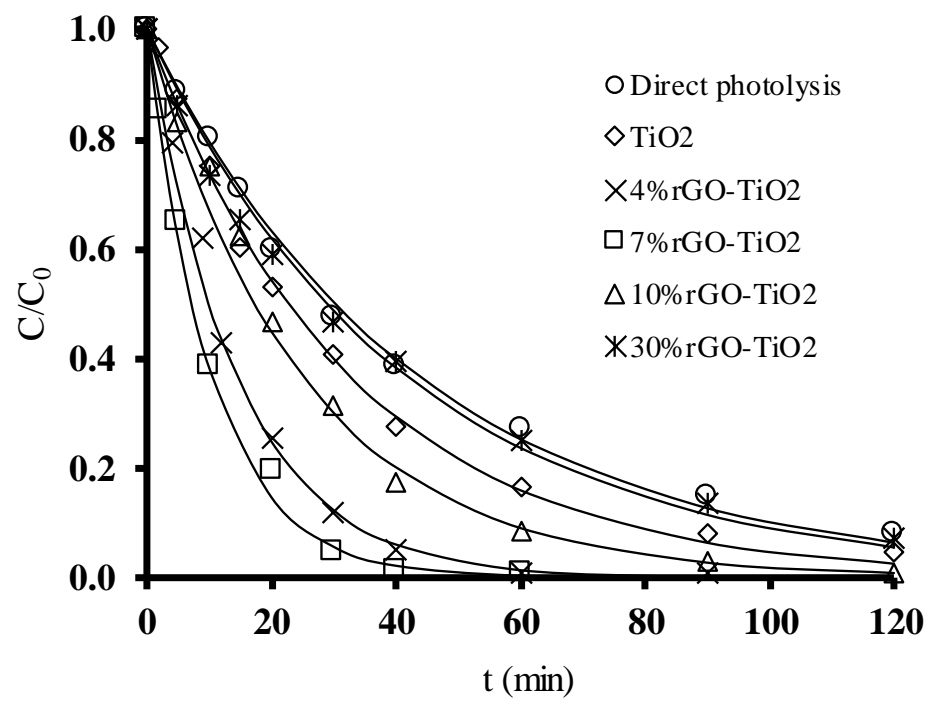

Figure 12. Photodegradation kinetics of EtP under $\mathrm{UV}$ radiation in the presence of $\mathrm{rGO}-\mathrm{TiO}_{2}$ composites

\begin{tabular}{|c|c|c|c|c|c|}
\hline System & $t_{1 / 2}{ }^{a}(\min )$ & $t_{90 \%} b$ (min) & $K^{c}\left(\min ^{-1}\right)$ & $\operatorname{EtP}_{40 \min } \mathrm{d}(\%)$ & $\mathrm{TOC}_{40 \min } \mathrm{e}(\%)$ \\
\hline UV & 30.2 & 100.4 & 0.023 & 61.5 & 14.0 \\
\hline $\mathrm{TiO}_{2}$ & 22.4 & 75.2 & 0.031 & 72.5 & 21.8 \\
\hline $4 \% \mathrm{rGO}-\mathrm{TiO}_{2}$ & 10.4 & 34.4 & 0.067 & 95.4 & 44.7 \\
\hline $7 \%$ rGO-TiO & 7.2 & 23.9 & 0.096 & 98.6 & 56.6 \\
\hline $10 \% \mathrm{rGO}^{-\mathrm{TiO}_{2}}$ & 17.2 & 57.4 & 0.040 & 82.4 & 34.5 \\
\hline $30 \%$ rGO- $\mathrm{TiO}_{2}$ & 28.9 & 96.1 & 0.024 & 60.7 & 24.9 \\
\hline
\end{tabular}
as a function of treatment time. $[\mathrm{EtP}]_{0}=0.30 \times 10^{-3} \mathrm{~mol} / \mathrm{L},[\text { catalyst }]_{0}=0.7 \mathrm{~g} / \mathrm{L}$.

Table 8. Experimental results obtained from EtP photodegradation under UV radiation in the presence of different $\mathrm{rGO}-\mathrm{TiO}_{2}$ composites $[\mathrm{EtP}]_{0}=0.30 \times 10^{-3} \mathrm{~mol} / \mathrm{L}$, [catalyst $]_{0}=0.7 \mathrm{~g} / \mathrm{L}$.

${ }^{\mathrm{a}}$ Time required to halve the initial concentration of EtP. ${ }^{\mathrm{b}}$ Time required to degrade $90 \%$ of the initial concentration of EtP. ${ }^{c}$ Degradation rate constant. ${ }^{d}$ Percentage degradation after $40 \mathrm{~min}$. ${ }^{\text {e }}$ Percentage mineralization after $40 \mathrm{~min}$. 
As observed in Table 8, the presence of $\mathrm{TiO}_{2}$ in the medium increases EtP photodegradation in comparison to direct photolysis. The percentage of rGO in the composite has a major effect on the photocatalytic performance. Based on the photodegradation rate, greater catalytic activity is observed for $7 \% \mathrm{rGO}-\mathrm{TiO}_{2}, 4 \% \mathrm{rGO} / \mathrm{TiO}_{2}$, and $10 \% \mathrm{rGO}-\mathrm{TiO}_{2}$ composites than for $\mathrm{TiO}_{2}$ alone. The time to degrade $90 \%$ EtP decreases with the use of $\mathrm{rGO}^{-\mathrm{TiO}_{2}}$ composites, and is shortest $(23.9 \mathrm{~min})$ when the $7 \% \mathrm{rGO}^{-\mathrm{TiO}_{2}}$ sample is used. According to the results in Table 8, the performance of EtP photocatalytic degradation decreases in the order: $7 \% \mathrm{rGO}-\mathrm{TiO}_{2}>4 \% \mathrm{rGO}^{-\mathrm{TiO}_{2}}>10 \% \mathrm{rGO}-\mathrm{TiO}_{2}>\mathrm{TiO}_{2}>30 \%$ $\mathrm{rGO}-\mathrm{TiO}_{2}>\mathrm{UV}$. At $40 \mathrm{~min}$, the percentage degradation of EtP is always higher than the percentage removal of TOC, indicating that not all degraded EtP is mineralized during the catalytic degradation process, obtaining by-products with a lower molecular weight than that of EtP.

The results obtained demonstrate that the presence of $\mathrm{rGO}$ in the $\mathrm{TiO}_{2}$ composite considerably enhances the photocatalytic activity of $\mathrm{TiO}_{2}$, increasing the degradation rate constant from 0.031 to $0.096 \mathrm{~min}^{-1}$ in the presence of $7 \% \mathrm{rGO}$. The percentage degradation of EtP at $40 \mathrm{~min}$ is $72.5 \%$ for $\mathrm{TiO}_{2}$ and rises to $98.6 \%$ for $7 \% \mathrm{rGO}^{-\mathrm{TiO}_{2}}$. These results evidence the positive role of rGO in EtP photodegradation. The presence of $\mathrm{rGO}$ sheets in the $\mathrm{TiO}_{2}$ composite favors its photocatalytic activity in the following four ways: (i) rGO sheets improve the adsorption capacity of the $\mathrm{rGO} / \mathrm{TiO}_{2}$ composite by increasing its surface area (Table 1), thereby increasing the concentration of EtP molecules close to the active sites in $\mathrm{TiO}_{2}$ and thereby improving photodegradation; (ii) graphene is an electron acceptor due to its two-dimension $\pi$ conjugation structure, and the excited electrons of $\mathrm{TiO}_{2}$ can rapidly transfer from the conduction band of $\mathrm{TiO}_{2}$ to $\mathrm{rGO}$ in $\mathrm{rGO} / \mathrm{TiO}_{2}$ composites, effectively suppressing the recombination of photogenerated charge carriers and enhancing EtP degradation; (iii) rGO can act as a sensitizer by donating electrons to $\mathrm{TiO}_{2}$. These electrons are excited by $\mathrm{UV}$ radiation photon, generating superoxide radicals through reduction of the adsorbed molecular oxygen; in addition, positively charged $\mathrm{rGO}$ sheets attract $\mathrm{TiO}_{2}$ electrons and create positive holes in the valence band of $\mathrm{TiO}_{2}$, which react with the water adsorbed to generate hydroxyl radicals; and (iv) the presence of $\mathrm{C}-\mathrm{O}-\mathrm{Ti}$ bonds in composites reduces the band-gap energy to a value of $2.55 \mathrm{eV}$, as reported in Section 2.7, facilitating the transition of electrons from the valence to the conduction band and increasing the concentration of radicals generated $[38,80]$.

The results in Table 8 demonstrate that the photocatalytic activity of composite materials depends on their rGO content. Thus, the activity increases when the rGO rises from 4 to $7 \%$ and decreases when it rises to $10 \%$, and this decrease is much higher when the sample contains $30 \%$ rGO, with the photoactivity being lower for $30 \% \mathrm{rGO}^{-\mathrm{TiO}_{2}}$ than for $\mathrm{TiO}_{2}$. The mass ratio of $\mathrm{rGO}$ to $\mathrm{TiO}_{2}$ affects the photodegradation process performance because both materials have a synergic effect on pollutant adsorption and photocatalysis. Depending on the type of composite, there is an optimal $\mathrm{rGO} / \mathrm{TiO}_{2}$ ratio that achieves maximum pollutant degradation due to the uniformity of titanium dioxide anchoring. When this optimal rGO amount is exceeded, the performance of the process decreases, because an excess of rGO particles can cover the active sites on the $\mathrm{TiO}_{2}$ surface or act as recombination centers. This favors the aggregation of $\mathrm{rGO}-\mathrm{TiO}_{2}$ composites, blocking light to the $\mathrm{TiO}_{2}$ surface and restricting the $\mathrm{rGO}-\mathrm{TiO}_{2}$ contact, thereby reducing the synergic effect $[31,60,80]$.

The above findings indicate that the optimal rGO percentage in $\mathrm{TiO}_{2}$ composites is around $7 \%$ in the present system. Comparison of characteristics of the four composite samples under study shows that $7 \% \mathrm{rGO}-\mathrm{TiO}_{2}$ has the smallest crystal size, $17.6 \mathrm{~nm}$ (Table 3), and the lowest $\mathrm{I}_{\mathrm{D}} / \mathrm{I}_{\mathrm{G}}$ ratio, 0.95 (Table 5). These two characteristics favor the behavior of $7 \% \mathrm{rGO}^{-\mathrm{TiO}_{2}}$, because a smaller crystal size increases the number of active sites exposed to light and a lower $\mathrm{I}_{\mathrm{D}} / \mathrm{I}_{\mathrm{G}}$ value indicates a higher proportion of carbon atoms with $\mathrm{sp}^{2}$ hybridization, favoring the electronic conductivity of the sample and, therefore, its photoactivity.

With respect to the behavior of rGO-P25 composite materials, Figure S7 depicts the degradation kinetics of EtP, and Table 9 lists the values of kinetic parameters obtained. The photocatalytic activity of P25 (Table 9) is lower than that of the $\mathrm{TiO}_{2}$ prepared in this study (Table 8), and rGO-P25 composite materials are much less active in EtP photodegradation compared with $\mathrm{rGO}-\mathrm{TiO}_{2}$. 
Numerous authors have studied the reference material P25 (manufactured by Degussa but now by Evonik Industries), a mixed-phase $\mathrm{TiO}_{2}$ photocatalyst $(85.9 \mathrm{wt} \%$ anatase and $14.1 \mathrm{wt} \%$ rutile), for comparison with the materials synthetized in each laboratory $[81,82]$. The P25 sample is a heterojunction photocatalyst of $\mathrm{TiO}_{2}$. Although anatase is commonly considered the most active phase of $\mathrm{TiO}_{2}$ in photocatalysis, it has been demonstrated that the binding of two phases (anatase with brookite or anatase with rutile) improves the photocatalytic activity in comparison to anatase alone. This improvement is attributable to its effect on the separation of charge carriers, because it traps electrons in rutile phase and minimizes electron recombination. This is similar to the heterojunction between different photocatalysts [83-85]. All of the present results indicate that the $\mathrm{TiO}_{2}$ prepared for this study is a more active photocatalyst for degrading EtP in comparison to commercial P25; this may be due in part to the larger surface area (Table 1) and smaller crystal size (Tables 3 and 4) of $\mathrm{TiO}_{2}$ than of $\mathrm{P} 25$. These differences also make $\mathrm{rGO}-\mathrm{TiO}_{2}$ composites more photoactive than the corresponding rGO-P25 composites.

Table 9. Experimental results obtained from EtP photodegradation with the UV/rGO-P25 system. $[\mathrm{EtP}]_{0}=0.30 \times 10^{-3} \mathrm{~mol} / \mathrm{L}$. [catalyst $]_{0}=0.7 \mathrm{~g} / \mathrm{L}$.

\begin{tabular}{|c|c|c|c|c|}
\hline System & $t_{1 / 2}(\min )$ & $t_{90 \%}(\min )$ & $\mathrm{k}\left(\min ^{-1}\right)$ & $\mathrm{EtP}_{40 \text { min }}(\%)$ \\
\hline UV & 30.2 & 100.4 & 0.023 & 61.5 \\
\hline P25 & 28.1 & 93.3 & 0.025 & 64.5 \\
\hline $4 \%$ rGO-P25 & 21.9 & 72.9 & 0.032 & 74.4 \\
\hline $10 \%$ rGO-P25 & 34.5 & 114.6 & 0.020 & 53.6 \\
\hline
\end{tabular}

Table S4 summarizes the most significant results reported from the literature when using other photocatalysts and UV or solar radiation for the removal of parabens from water. It can be concluded that $7 \%$ rGO-TiO 2 photocatalyst is the most active in EtP photodegradation.

\section{Materials and Methods}

\subsection{Reagents}

All chemical reagents used in this study (natural graphite, potassium permanganate, sodium nitrate, hydrogen peroxide [33\%], sulfuric acid, hydrochloric acid, ethanol, titanium isopropoxide, ethylparaben, and triethanolamine) were high-purity analytical grade reagents and were supplied by Sigma-Aldrich. Titanium(IV) oxide (Aeroxide P25) was purchased from Acros Organics. All solutions were prepared using ultrapure water obtained with Milli-Q equipment $(18.2 \mathrm{M} \Omega \mathrm{cm})$.

\subsection{Synthesis of Graphene Oxide}

GO preparation was based on the modified Hummers method [37,53]. Briefly, $120 \mathrm{~mL} \mathrm{H}_{2} \mathrm{SO}_{4}$ conc, $2.5 \mathrm{~g}$ graphite, and $2.5 \mathrm{~g} \mathrm{NaNO}_{3}$ were added in a beaker under agitation and in a cold bath. Subsequently, $15 \mathrm{~g} \mathrm{KMnO}_{4}$ was added very slowly in small doses at $<20^{\circ} \mathrm{C}$. The suspension was continuously agitated for $2 \mathrm{~h}$ at $35^{\circ} \mathrm{C}$. Next, $325 \mathrm{~mL}$ of water was added to the cold mixture, raising the temperature to $90{ }^{\circ} \mathrm{C} ; 8.83 \mathrm{~mL} \mathrm{H}_{2} \mathrm{O}_{2} 33 \%$ was then added to reduce $\mathrm{KMnO}_{4}$ to soluble manganese ions, maintaining the agitation for $30 \mathrm{~min}$. The oxidized material was washed with $10 \% \mathrm{HCl}$ and the suspension was centrifuged and washed several times with water until reaching neutral $\mathrm{pH}$. The resulting product was oven-dried at $60^{\circ} \mathrm{C}$ for $24 \mathrm{~h}$ to obtain graphite oxide, which was dispersed in $250 \mathrm{~mL}$ water and sonicated for $1 \mathrm{~h}$. The sonicated dispersion was centrifuged for $30 \mathrm{~min}$ at $8000 \mathrm{rpm}$ to separate the non-exfoliable graphite oxide particles from the GO particles remaining in the solution.

\subsection{Synthesis of $r \mathrm{GO}-\mathrm{TiO}_{2}$ Composites}

rGO- $\mathrm{TiO}_{2}$ composites were prepared using a hydrothermal method [41]. Briefly, $3.7 \mathrm{~mL}$ titanium isopropoxide was added to $3.3 \mathrm{~mL}$ triethanolamine in a $25 \mathrm{~mL}$ volumetric flask in order to obtain 
a $0.5 \mathrm{M}$ Ti(IV) solution. The $\mathrm{rGO}-\mathrm{TiO}_{2}$ composites were obtained by adding different amounts of a GO dispersion $(1 \mathrm{mg} / \mathrm{mL})$ to $42.9 \mathrm{~mL}$ of a water:ethanol (1:14) mixture under continuous agitation. Subsequently, $8.6 \mathrm{~mL}$ of the $0.5 \mathrm{M} \mathrm{Ti}(\mathrm{IV})$ solution was added, agitating for $24 \mathrm{~h}$ at room temperature to obtain a homogeneous solution, which was then placed in a $120 \mathrm{~mL}$ Teflon vessel within a stainless steel reactor (Parr Acid Digestion Vessel, Model 4748) and heated at $180{ }^{\circ} \mathrm{C}$ for $24 \mathrm{~h}$. The resulting solid was washed three times with ethanol, centrifuged at 13,000 rpm for $10 \mathrm{~min}$, and then oven-dried at $60^{\circ} \mathrm{C}$.

The composite materials obtained were designated $x \mathrm{rGO}-\mathrm{TiO}_{2}$, with $\mathrm{x}$ being the $\mathrm{GO}$ content $(4 \%$, $7 \%, 10 \%$, or $30 \%$ ). Pure samples of $\mathrm{TiO}_{2}$ samples (without $\mathrm{GO}$ addition) and $\mathrm{rGO}$ were also prepared using the same experimental method (without titanium isopropoxide).

rGO-P25 composites were prepared by a simple hydrothermal method [86]. Briefly, different amounts of $\mathrm{GO}$ were added to a mixture of water $(60 \mathrm{~mL})$ and ethanol $(30 \mathrm{~mL})$ and sonicated for $30 \mathrm{~min}$. Next, $300 \mathrm{mg}$ P25 were added to the solution, which was agitated for $2 \mathrm{~h}$ to obtain a homogeneous mixture. This mixture was placed in a $120 \mathrm{~mL}$ Teflon vessel within a stainless-steel reactor (Parr Acid Digestion Vessel, Model 4748) and heated at $120^{\circ} \mathrm{C}$ for $3 \mathrm{~h}$ to simultaneously achieve GO reduction and P25 deposition on rGO sheets. Finally, the resulting composite material was recovered by filtration, washed several times with deionized water, and dried at $70^{\circ} \mathrm{C}$ for $12 \mathrm{~h}$.

\subsection{Characterization Techniques}

Samples were texturally characterized by $\mathrm{N}_{2}$ adsorption at $-196^{\circ} \mathrm{C}$ with ASAP 2020 equipment (Micromeritics, Norcross, GA, USA). The BET surface area $\left(\mathrm{S}_{\mathrm{BET}}\right)$ was calculated according to the adsorption isotherms. Dubinin-Radushkevich (DR) and Stoeckli equations were applied to determine micropore volume $\left(\mathrm{V}_{0}\right)$ and mean micropore width $\left(\mathrm{L}_{0}\right)$. The mesopore volume was obtained as the difference in the amount of $\mathrm{N}_{2}$ adsorbed at a relative pressure of 0.95 and $\mathrm{V}_{0}$.

Thermogravimetric analysis was conducted using Mettler Toledo equipment, model TGA/DSC 1 Start System (Mettler Toledo, Columbus, Ohio, USA), heating the sample from 30 to $1000{ }^{\circ} \mathrm{C}$ in air atmosphere at a heating rate of $20^{\circ} \mathrm{C} / \mathrm{min}$.

Powder XRD experiments were conducted in PANalytical Empyrean XRD equipment (Empyrean, Almelo, The Netherlands) using $\mathrm{CuK} \alpha$ radiation. Diffractograms were analyzed by consulting the files of the International Centre for Diffraction Data (Joint Committee on Powder Diffraction Standards). Diffraction patterns were recorded between $5^{\circ}$ and $80^{\circ}(2 \theta)$ with passage size of $0.01^{\circ}$ and integration time of $100 \mathrm{~s}$.

FTIR spectra were recorded with a Bruker Vertex 70 spectrometer (Bruker, Ettlingen, Germany) in the range $4000-400 \mathrm{~cm}^{-1}$. Raman spectra were determined using a Renishaw inVia confocal Raman microscope. The excitation source was ionized Ar laser $(\lambda=514.5 \mathrm{~nm})$ in a measurement range of $100-3500 \mathrm{~cm}^{-1}$. A $50 \times$ microscope objective was used, and the laser power was $1 \mathrm{~mW}$. Spectral lines were fitted to Lorentzian functions with OriginPro 8.6.0 (32bit) SR2 b98 (Originlab Corpotation, Northampton, USA).

XPS experiments were conducted using an X-ray photoelectron spectrometer with AlK $\alpha$ anode $\mathrm{X}$-ray source and hemispherical electron analyzer (PHI 5000 Versa Probe II, Chanhassen, MN, USA). The X-ray source was operated at $450 \mathrm{~W}$. The regions analyzed were always $\mathrm{C} 1 \mathrm{~s}, \mathrm{O} 1 \mathrm{~s}$, and Ti 2p. The signals for each region were deconvoluted using Gaussian-Lorentzian asymmetrical addition type functions to determine the number of components, the bond energy (BE) of peaks, and their area (quantitative analysis). The $\mathrm{BE}$ of the $\mathrm{C} 1 \mathrm{~s}$ peak at $284.6 \mathrm{eV}$ was considered the reference peak.

UV-Vis diffuse reflectance spectra for $\mathrm{TiO}_{2}$ and composites were obtained in the measurement range of 200-2000 nm at $25^{\circ} \mathrm{C}$. Powder samples were analyzed in a Varian Cary 4000 spectrophotometer (Varian, Mulgrave, Australia) equipped with a spherical diffuse reflectance accessory.

Photoluminescence (PL) spectroscopy characterization was performed using a CARY VARIAN (Agilent, Santa Clara, CA, USA) fluorescence spectrophotometer equipped with Xe lamp as excitation source, exciting PL spectra to $264 \mathrm{~nm}$ wavelength at room temperature (293 K). 


\subsection{Photocatalytic Experiments}

Experiments were conducted to investigate the photocatalytic activity of the prepared composites in EtP degradation. They were performed in a UV laboratory reactor system 2 (UV Consulting Peschl, Mainz, Germany) equipped with medium-pressure mercury vapor lamp (TQ 150, nominal power $150 \mathrm{~W})$, pouring $700 \mathrm{~mL}$ of EtP solution $(0.3 \mathrm{mM})$ with $0.7 \mathrm{~g} / \mathrm{L}$ of $\mathrm{rGO}^{-\mathrm{TiO}_{2}}$ into the reactor. EtP concentrations were determined at different time points using a high-performance liquid chromatograph (Thermo-Fisher) equipped with a UV800 photodiode detector (column: Hypersil GOLD $25 \times 4.6 \mathrm{~mm}$; mobile phase: $50: 50$ methanol: acidic water [0.01\% $\mathrm{HCOOH}]$; flow rate: $1 \mathrm{~mL} / \mathrm{min}$, injection volume: $20 \mu \mathrm{L}$; UV detector wavelength: $254 \mathrm{~nm}$ ). For each experiment, the photoreactor was activated after stabilizing the lamp and controlling the temperature $\left(25^{\circ} \mathrm{C}\right)$, and $2 \mathrm{~mL}$ aliquots were then withdrawn from the reactor at different time points to measure concentrations of EtP and total organic carbon (TOC). EtP mineralization was followed by TOC measurements, as described elsewhere [87].

\section{Conclusions}

rGO-TiO $\mathrm{T}_{2}$ composites with different percentages of rGO were successfully prepared using a simple hydrothermal method. The results obtained demonstrated the effective reduction of GO, the formation of pure anatase phase, and the formation of $\mathrm{Ti}-\mathrm{O}-\mathrm{C}$ bonds on composite surfaces. The surface area and porosity are more developed in the $\mathrm{rGO}^{-} \mathrm{TiO}_{2}$ composites than in the GO-P25 composites. The highest $\mathrm{Ti} / \mathrm{C}$ ratio is observed for the $7 \% \mathrm{rGO}-\mathrm{TiO}_{2}$ composite, due to a superior $\mathrm{rGO}$ sheets dispersion in the $\mathrm{TiO}_{2}$ matrix. All rGO-TiO ${ }_{2}$ composites obtained behave as semiconductor materials $(\mathrm{Eg} \leq 3.1 \mathrm{eV})$, and a higher percentage of rGO produces a reduction in band gap energies due to the formation of Ti-O-C bonds.

The highest photocatalytic activity for EtP degradation under UV radiation is achieved with the composite containing $7 \% \mathrm{rGO}\left(7 \% \mathrm{rGO}-\mathrm{TiO}_{2}\right)$, which reaches $98.6 \%$ degradation after $40 \mathrm{~min}$ of irradiation. However, a higher graphene content leads to the aggregation of graphene nanosheets and $\mathrm{TiO}_{2}$ nanoparticles, reducing the light absorption capacity and EtP photodegradation.

The presence of two phases (anatase and rutile) in P25, and the smaller surface area and larger crystal size in rGO-P25 versus $\mathrm{rGO}-\mathrm{TiO}_{2}$ composites may be responsible for the lower photocatalytic activity of the former in EtP removal. In the rGO-P25 composites, photocatalytic EtP degradation reaches the maximum value with a rGO content of only $4 \%$.

Finally, it can be concluded that this type of photoactive composites, based on $\mathrm{rGO}$ and $\mathrm{TiO}_{2}$ and with an adequate content of rGO, can be highly effective for the UV photodegradation of emerging organic pollutants such as parabens in water.

Supplementary Materials: The following are available online at http://www.mdpi.com/2073-4344/10/5/520/s1, Figure S1: Thermogravimetric analysis curves for P25 and x\% rGO-P25, Figure S2: XRD patterns for rGO-P25 composites, Figure S3: FTIR spectra of P25 and rGO-P25 composites, Figure S4: Raman spectra of P25 and rGO-P25 composites, Figure S5: XPS profiles of rGO-P25 composites: (a) C 1s spectra; (b) O 1s spectra and (c) Ti 2p spectra. Continuous red line: experimental profile; discontinuous black line: fitted profile, Figure S6: Schematic diagram of the energy levels for $\mathrm{rGO}$ and $\mathrm{TiO}_{2}$, Figure S7: Photodegradation kinetics of EtP under UV radiation in the presence of rGO-P25 composites as a function of treatment time. $[\mathrm{EtP}]_{0}=0.30 \times 10^{-3} \mathrm{~mol} / \mathrm{L}$, $[\mathrm{catalyst}]_{0}$

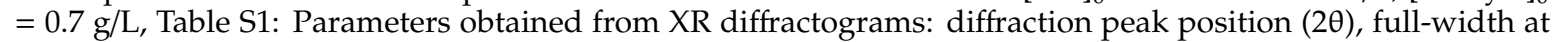
half maximum (FWHM), and crystal size $\left(\mathrm{D}_{101}\right)$, Table S2: Parameters obtained from Raman spectra for P25 and rGO-P25 composites, Table S3: Ti/C, $\mathrm{A}_{\mathrm{C}-\mathrm{O}} / \mathrm{A}_{\mathrm{C}-\mathrm{C}}$ ratios, species percentages, and bond energies (in brackets, $\mathrm{eV}$ ) obtained by XPS analysis, Table S4: Results of the application of different photocatalysts for the removal of parabens from water [88].

Author Contributions: M.A.Á., M.V.L.-R., J.R.-U. and M.S.-P. conceived and designed the experiments; M.R.-M. and G.C.-Q. performed the experiments; M.R.-M., G.C.-Q. and M.A.Á. analyzed the data; M.A.Á., M.V.L.-R., J.R.-U. and M.S.-P. wrote the paper. All authors have read and agreed to the published version of the manuscript.

Funding: This research was funded by Spanish Ministry of Economy, Industry and Competitiveness and FEDER (grant number CTQ2016-80978-C2-1-R), Asociación Universitaria Iberoamericana de Postgrado (AUIP) and University of Jaen. 
Acknowledgments: This work was supported by the Spanish Ministry of Economy, Industry and competitiveness and by FEDER (Project CTQ2016-80978-C2-1-R). M.R.-M. thanks to the Asociación Universitaria Iberoamericana de Postgrado (AUIP) and the University of Jaen for the grant awarded and the financial support.

Conflicts of Interest: The authors declare no conflict of interest.

\section{References}

1. Albero, B.; Pérez, R.A.; Sánchez-Brunete, C.; Tadeo, J.L. Occurrence and analysis of parabens in municipal sewage sludge from wastewater treatment plants in Madrid (Spain). J. Hazard. Mater. 2012, 48, 239-240. [CrossRef] [PubMed]

2. Council Directive 76/768/EEC of 27 July 1976. Available online: https://eur-lex.europa.eu/legal-content/EN/ TXT/HTML/?uri=CELEX:31976L0768\&from=EN (accessed on 17 February 2020).

3. Gomes, J.F.; Lopes, A.; Gmurek, M.; Quinta-Ferreira, R.M.; Martins, R.C. Study of the influence of the matrix characteristics over the photocatalytic ozonation of parabens using Ag- $\mathrm{TiO}_{2}$. Sci. Total Environ. 2019, 646, 1468-1477. [CrossRef] [PubMed]

4. Nian, P.; Peng, L.; Feng, J.; Han, X.; Cui, B.; Lu, S.; Zhang, J.; Liu, Q.; Zhang, A. Aqueous methylparaben degradation by dielectric barrier discharge induced non-thermal plasma combined with ZnO-rGO nanosheets. Sep. Purif. Technol. 2019, 211, 832-842. [CrossRef]

5. Terasaki, M.; Makino, M.; Tatarazako, N. Acute toxicity of parabens and their chlorinated by-products with Daphnia magna and Vibrio fischeri bioassays. J. Appl. Toxicol. 2009, 29, 242-247. [CrossRef] [PubMed]

6. Rostamifasih, Z.; Pasalari, H.; Mohammadi, F.; Esrafili, A. Heterogeneous catalytic degradation of methylparaben using persulfate activated by natural magnetite; optimization and modeling by response surface methodology. J. Chem. Technol. Biotechnol. 2019, 94, 1880-1892. [CrossRef]

7. Chin, Y.P.; Mohamad, S.; Abas, M.R.B. Removal of parabens from aqueous solution using $\beta$-cyclodextrin cross-linked polymer. Int. J. Mol. Sci. 2010, 11, 3459-3471. [CrossRef]

8. Mashile, G.P.; Mpupa, A.; Nqombolo, A.; Dimpe, K.M.; Nomngongo, P.N. Recyclable magnetic waste tyre activated carbon-chitosan composite as an effective adsorbent rapid and simultaneous removal of methylparaben and propylparaben from aqueous solution and wastewater. J. Water Process. Eng. 2020, 33, 101011. [CrossRef]

9. Bernal, V.; Giraldo, L.; Moreno-Piraján, J.C.; Balsamo, M.; Erto, A. Mechanisms of methylparaben adsorption onto activated carbons: Removal tests supported by a calorimetric study of the adsorbent-adsorbate interactions. Molecules 2019, 24, 413. [CrossRef]

10. Domínguez, J.R.; Munõz, M.J.; Palo, P.; González, T.; Peres, J.A.; Cuerda-Correa, E.M. Fenton advanced oxidation of emerging pollutants: Parabens. Int. J. Energy Environ. Eng. 2014, 5, 89. [CrossRef]

11. Martins, R.C.; Gmurek, M.; Rossi, A.F.; Corceiro, V.; Costa, R.; Quinta-Ferreira, M.E.; Ledakowicz, S.; Quinta-Ferreira, R.M. Application of Fenton oxidation to reduce the toxicity of mixed parabens. Water Sci. Technol. 2016, 74, 1867-1875. [CrossRef]

12. Frontistis, Z.; Antonopoulou, M.; Yazirdagi, M.; Kilinc, Z.; Konstantinou, I.; Katsaounis, A.; Mantzavinos, D. Boron-doped diamond electrooxidation of ethyl paraben: The effect of electrolyte on by-products distribution and mechanisms. J. Environ. Manag. 2017, 195, 148-156. [CrossRef] [PubMed]

13. Tay, K.; Rahman, N.; Abas, M. Ozonation of parabens in aqueous solution: Kinetics and mechanism of degradation. Chemosphere 2020, 81, 1446-1453. [CrossRef] [PubMed]

14. Pipolo, M.; Gmurek, M.; Corceiro, V.; Costa, R.; Quinta-Ferreira, M.E.; Ledakowicz, S.; Quinta-Ferreira, R.M.; Martins, R.C. Ozone-based technologies for parabens removal from water: Toxicity assessment. Ozone Sci. Eng. 2017, 39, 233-243. [CrossRef]

15. Hansen, K.; Andersen, $\mathrm{H}$. Energy effectiveness of direct $\mathrm{UV}$ and $\mathrm{UV} / \mathrm{H}_{2} \mathrm{O}_{2}$ treatment of estrogenic chemicals in biologically treated sewage. Int. J. Photoenergy 2012, 2012, 270320. [CrossRef]

16. Gmurek, M.; Rossi, A.F.; Martins, R.C.; Quinta-Ferreira, R.M.; Ledakowicz, S. Photodegradation of single and mixture of parabens-kinetic, by-products identification and cost-efficiency analysis. Chem. Eng. J. 2015, 276, 303-314. [CrossRef]

17. Gomes, J.; Leal, I.; Bednarczyk, K.; Gmurek, M.; Stelmachowski, M.; Zaleska-Medynska, A.; Bastos, F.C.; Quinta-Ferreira, M.E.; Costa, R.; Quinta-Ferreira, R.M.; et al. Detoxification of parabens using UV-A enhanced by noble metals- $\mathrm{TiO}_{2}$ supported catalysts. J. Environ. Chem. Eng. 2017, 5, 3065-3074. [CrossRef] 
18. Daghrir, R.; Dimboukou-Mpira, A.; Seyhi, B.; Drogui, P. Photosonochemical degradation of butyl-paraben: Optimization, toxicity and kinetic studies. Sci. Total Environ. 2014, 490, 223-234. [CrossRef]

19. Gomes, J.; Leal, I.; Bednarczyk, K.; Gmurek, M.; Stelmachowski, M.; Diak, M.; Quinta-Ferreira, M.E.; Costa, R.; Quinta-Ferreira, R.M.; Martins, R.C. Photocatalytic ozonation using doped $\mathrm{TiO}_{2}$ catalysts for the removal of parabens in water. Sci. Total Environ. 2017, 609, 329-340. [CrossRef]

20. Chiu, Y.-H.; Chang, T.-F.M.; Chen, C.-Y.; Sone, M.; Hsu, Y.-J. Mechanistic insights into photodegradation of organic dyes using heterostructure photocatalysts. Catalysts 2019, 9, 430. [CrossRef]

21. Tang, B.; Chen, H.; Peng, H.; Wang, Z.; Huang, W. Graphene modified $\mathrm{TiO}_{2}$ composite photocatalysts: Mechanism, progress and perspective. Nanomaterials 2018, 8, 105. [CrossRef]

22. Fang, M.J.; Tsao, C.W.; Hsu, Y.J. Semiconductor nanoheterostructures for photoconversion applications. J. Phys. D Appl. Phys. 2020, 53, 143001. [CrossRef]

23. Martins, A.S.; Marques Cordeiro-Junior, P.J.; Garcia Bessegato, G.; Fernandes Carneiro, J.; Boldrin Zanoni, M.V.; de Vasconcelos Lanza, M.R. Electrodeposition of $\mathrm{WO}_{3}$ on Ti substrate and the influence of interfacial oxide layer generated in situ: A photoelectrocatalytic degradation of propyl paraben. Appl. Surf. Sci. 2019, 464, 664-672. [CrossRef]

24. Gomes, J.F.; Lopes, A.; Bednarczyk, K.; Gmurek, M.; Stelmachowski, M.; Zaleska-Medynska, A.; Quinta-Ferreira, M.E.; Costa, R.; Quinta-Ferreira, R.M.; Martins, R.C. Effect of noble metals (Ag, Pd, Pt) loading over the efficiency of $\mathrm{TiO}_{2}$ during photocatalytic ozonation on the toxicity of parabens. Chemengineering 2018, 2, 4. [CrossRef]

25. Cruz, M.; Gomez, C.; Duran-Valle, C.J.; Pastrana-Martínez, L.M.; Faria, J.L.; Silva, A.M.T.; Faraldos, M.; Bahamonde, A. Bare $\mathrm{TiO}_{2}$ and graphene oxide $\mathrm{TiO}_{2}$ photocatalysts on the degradation of selected pesticides and influence of the water matrix. Appl. Surf. Sci. 2017, 416, 1013-1021. [CrossRef]

26. Lin, Y.; Ferronato, C.; Deng, N.; Wu, F.; Chovelon, J.M. Photocatalytic degradation of methylparaben by $\mathrm{TiO}_{2}$ : Multivariable experimental design and mechanism. Appl. Catal. B Environ. 2009, 88, 32-41. [CrossRef]

27. Atheba, P.; Drogui, P.; Seyhi, B.; Robert, D. Photo-degradation of butyl parahydroxybenzoate by using $\mathrm{TiO}_{2}$-supported catalyst. Water Sci. Technol. 2013, 67, 2141-2147. [CrossRef]

28. Petala, A.; Frontistis, Z.; Antonopoulou, M.; Konstantinou, I.; Kondarides, D.I.; Mantzavinos, D. Kinetics of ethyl paraben degradation by simulated solar radiation in the presence of $\mathrm{N}$-doped $\mathrm{TiO}_{2}$ catalysts. Water Res. 2015, 81, 157-166. [CrossRef]

29. Frontistis, Z.; Antonopoulou, M.; Venieri, D.; Dailianis, S.; Konstantinou, I.; Mantzavinos, D. Solar photocatalytic decomposition of ethyl paraben in zinc oxide suspensions. Catal. Today 2017, 280, 139-148. [CrossRef]

30. Tu, S.; Lu, M.; Xiao, X.; Zheng, C.; Zhong, H.; Zuo, X.; Nan, J. Flower-like $\mathrm{Bi}_{4} \mathrm{O}_{5} \mathrm{I}_{2} / \mathrm{Bi}_{5} \mathrm{O}_{7} \mathrm{I}$ nanocomposite: Facile hydrothermal synthesis and efficient photocatalytic degradation of propylparaben under visible-light irradiation. RSC Adv. 2016, 6, 44552-44560. [CrossRef]

31. Petala, A.; Noe, A.; Frontistis, Z.; Drivas, C.; Kennou, S.; Mantzavinos, D.; Kondarides, D.I. Synthesis and characterization of $\mathrm{CoOx} / \mathrm{BiVO}_{4}$ photocatalysts for the degradation of propyl paraben. J. Hazard. Mater. 2019, 372, 52-60. [CrossRef]

32. Frontistis, Z.; Antonopoulou, M.; Petala, A.; Venieri, D.; Konstantinou, I.; Kondarides, D.I.; Mantzavinos, D. Photodegradation of ethyl paraben using simulated solar radiation and $\mathrm{Ag}_{3} \mathrm{PO}_{4}$ photocatalyst. J. Hazard. Mater. 2017, 323, 478-488. [CrossRef] [PubMed]

33. Kotzamanidi, S.; Frontistis, Z.; Binas, V.; Kiriakidis, G.; Mantzavinos, D. Solar photocatalytic degradation of propyl paraben in Al-doped $\mathrm{TiO}_{2}$ suspensions. Catal. Today 2018, 313, 148-154. [CrossRef]

34. Ngigi, E.M.; Nomngongo, P.N.; Ngila, J.C. Synthesis and application of Fe-doped $\mathrm{WO}_{3}$ nanoparticles for photocatalytic degradation of methylparaben using visible-light radiation and $\mathrm{H}_{2} \mathrm{O}_{2}$. Catal. Lett. 2019, 145, 49-60. [CrossRef]

35. Hu, Y.; Li, Z.; Yang, J.; Zhu, H. Degradation of methylparaben using BiOI-hydrogel composites activated peroxymonosulfate under visible light irradiation. Chem. Eng. J. 2019, 360, 200-211. [CrossRef]

36. Xiao, X.; Lu, M.; Nan, J.; Zuo, X.; Zhang, W.; Liu, S.; Wang, S. Rapid microwave synthesis of I-doped $\mathrm{Bi}_{4} \mathrm{O}_{5} \mathrm{Br}_{2}$ with significantly enhanced visible-light photocatalysis for degradation of multiple parabens. Appl. Catal. B Environ. 2017, 218, 398-408. [CrossRef] 
37. Pastrana-Martínez, L.M.; Morales-Torres, S.; Likodimos, V.; Figueiredo, J.L.; Faria, J.L.; Falaras, P.; Silva, A.M.T. Advanced nanostructured photocatalysts based on reduced graphene oxide- $\mathrm{TiO}_{2}$ composites for degradation of diphenhydramine pharmaceutical and methyl orange dye. Appl. Catal. B Environ. 2012, 123-124, 241-256.

38. Jiang, G.; Lin, Z.; Chen, C.; Zhu, L.; Chang, Q.; Wang, N.; Wei, W.; Tang, H. TiO 2 nanoparticles assembled on graphene oxide nanosheets with high photocatalytic activity for removal of pollutants. Carbon 2011, 49, 2693-2701. [CrossRef]

39. Alamelu, K.; Raja, V.; Shiamala, L.; Jaffar Ali, B.M. Biphasic $\mathrm{TiO}_{2}$ nanoparticles decorated graphene nanosheets for visible light driven photocatalytic degradation of organic dyes. Appl. Surf. Sci. 2018, 430, 145-154. [CrossRef]

40. Tayel, A.; Ramadan, A.R.; El Seoud, O.A. Titanium dioxide/graphene and titanium dioxide/graphene oxide nanocomposites: Synthesis, characterization and photocatalytic applications for water decontamination. Catalysts 2018, 8, 491. [CrossRef]

41. Chang, B.Y.S.; Huang, N.M.; An'amt, M.N.; Marlinda, A.R.; Norazriena, Y.; Muhamad, M.R.; Harrison, I.; Lim, H.N.; Chia, C.H. Facile hydrothermal preparation of titanium dioxide decorated reduced graphene oxide nanocomposite. Int. J. Nanomed. 2012, 7, 3379-3387.

42. Tan, L.L.; Ong, W.J.; Chai, S.P.; Mohamed, A.R. Reduced graphene oxide- $\mathrm{TiO}_{2}$ nanocomposite as a promising visible-light active photocatalyst for the conversion of carbon dioxide. Nanoscale Res. Lett. 2013, 8, 465. [CrossRef]

43. Ismail, A.A.; Geioushy, R.A.; Bouzid, H.; Al-Sayari, S.A.; Al-Hajry, A.; Bahnemann, D.W. TiO ${ }_{2}$ decoration of graphene layers for highly efficient photocatalyst: Impact of calcination at different gas atmosphere on photocatalytic efficiency. Appl. Catal. B Environ. 2013, 129, 62-70. [CrossRef]

44. Sher Shah, M.S.A.; Park, A.R.; Zhang, K.; Park, J.H.; Yoo, P.J. Green synthesis of biphasic $\mathrm{TiO}_{2}$-reduced graphene oxide nanocomposites with highly enhanced photocatalytic activity. ACS Appl. Mater. Interfaces 2012, 4, 3893-3901. [CrossRef] [PubMed]

45. Shen, J.; Yan, B.; Shi, M.; Ma, H.; Li, N.; Ye, M. One step hydrothermal synthesis of $\mathrm{TiO}_{2}$-reduced graphene oxide sheets. J. Mater. Chem. 2011, 21, 3415-3421. [CrossRef]

46. Ganguly, A.; Sharma, S.; Papakonstantinou, P.; Hamilton, J. Probing the thermal deoxygenation of graphene oxide using high-resolution in situ X-ray-based spectroscopies. J. Phys. Chem. C 2011, 115, 17009-17019. [CrossRef]

47. Dave, K.; Park, K.H.; Dhayal, M. Two-step process for programmable removal of oxygen functionalities of graphene oxide: Functional, structural and electrical characteristics. RSC Adv. 2015, 5, 95657-95665. [CrossRef]

48. Morais, A.; Longo, C.; Araujo, J.R.; Barroso, M.; Durrant, J.R.; Nogueira, A.F. Nanocrystalline anatase $\mathrm{TiO}_{2} /$ reduced graphene oxide composite films as photoanodes for photoelectrochemical water splitting studies: The role of reduced graphene oxide. Phys. Chem. Chem. Phys. 2016, 18, 2608-2616. [CrossRef]

49. Li, J.; Zhou, S.L.; Hong, G.B.; Chang, C.T. Hydrothermal preparation of P25-graphene composite with enhanced adsorption and photocatalytic degradation of dyes. Chem. Eng. J. 2013, 219, 486-491. [CrossRef]

50. Perera, S.D.; Mariano, R.G.; Vu, K.; Nour, N.; Seitz, O.; Chabal, Y.; Balkus, K.J. Hydrothermal synthesis of graphene- $\mathrm{TiO}_{2}$ nanotube composites with enhanced photocatalytic activity. ACS Catal. 2012, 2, 949-956. [CrossRef]

51. Ba-Abbad, M.M.; Kadhum, A.A.H.; Mohamad, A.B.; Takriff, M.S.; Sopian, K. Synthesis and catalytic activity of $\mathrm{TiO}_{2}$ nanoparticles for photochemical oxidation of concentrated chlorophenols under direct solar radiation. Int. J. Electrochem. Sci. 2012, 7, 4871-4888.

52. Kanta, U.-a.; Thongpool, V.; Sangkhun, W.; Wongyao, N.; Wootthikanokkhan, J. Preparations, characterizations, and a comparative study on photovoltaic performance of two different types of graphene $/ \mathrm{TiO}_{2}$ nanocomposites photoelectrodes. J. Nanomater. 2017, 2017, 2758294. [CrossRef]

53. Hummers, W.S.; Offeman, R.E. Preparation of graphitic oxide. J. Am. Chem. Soc. 1958, 80, 1339. [CrossRef]

54. Li, W.Q.; Liu, X.; Li, H.X. Hydrothermal synthesis of graphene/Fe ${ }^{3+}$-doped $\mathrm{TiO}_{2}$ nanowire composites with highly enhanced photocatalytic activity under visible light irradiation. J. Mater. Chem. A 2015, 3, 15214-15224. [CrossRef]

55. Liu, G.; Wang, R.; Liu, H.; Han, K.; Cui, H.; Ye, H. Highly dispersive nano-TiO ${ }_{2}$ in situ growing on functional graphene with high photocatalytic activity. J. Nanopart. Res. 2016, 18, 1-8. [CrossRef] 
56. Wojtoniszak, M.; Zielinska, B.; Chen, X.; Kalenczuk, R.J.; Mijowska, E. Synthesis and photocatalytic performance of $\mathrm{TiO}_{2}$ nanospheres-graphene nanocomposite under visible and UV light irradiation. J. Mater. Sci. 2012, 47, 3185-3190. [CrossRef]

57. Sampaio, M.J.; Silva, C.G.; Silva, A.M.T.; Martínez, L.M.P.; Han, C.; Torres, S.M.; Figueiredo, J.L.; Dionysiou, D.D.; Faria, J.L. Carbon-based $\mathrm{TiO}_{2}$ materials for the degradation of Microcystin-LA. Appl. Catal. B: Environ. 2015, 170-171, 74-82. [CrossRef]

58. Nguyen-Phan, T.D.; Pham, V.H.; Shin, E.W.; Pham, H.-D.; Kim, S.; Chung, J.S.; Kim, E.J.; Hur, S.H. The role of graphene oxide content on the adsorption-enhanced photocatalysis of titanium dioxide/graphene oxide composites. Chem. Eng. J. 2011, 170, 226-232. [CrossRef]

59. Karaolia, P.; Michael-Kordatou, I.; Hapeshi, E.; Drosou, C.; Bertakis, Y.; Christofilos, D.; Armatas, G.S.; Sygellou, L.; Schwartz, T.; Xekoukoulotakis, N.P.; et al. Removal of antibiotics, antibiotic-resistant bacteria and their associated genes by graphene-based $\mathrm{TiO}_{2}$ composite photocatalysts under solar radiation in urban wastewaters. Appl. Catal. B Environ. 2018, 224, 810-824. [CrossRef]

60. Long, M.; Qin, Y.; Chen, C.; Guo, X.; Tan, B.; Cai, W. Origin of visible light photoactivity of reduced graphene oxide/ $/ \mathrm{TiO}_{2}$ by in situ hydrothermal growth of undergrown $\mathrm{TiO}_{2}$ with graphene oxide. J. Phys. Chem. C 2013, 117, 16734-16741. [CrossRef]

61. Dresselhaus, M.S.; Jorio, A.; Hofmann, M.; Dresselhaus, G.; Saito, R. Perspectives on carbon nanotubes and graphene Raman spectroscopy. Nano Lett. 2010, 10, 751-758. [CrossRef]

62. Kudin, K.N.; Ozbas, B.; Schniepp, H.C.; Prud'homme, R.K.; Aksay, I.A.; Car, R. Raman spectra of graphite oxide and functionalized graphene sheets. Nano Lett. 2007, 8, 36-41. [CrossRef] [PubMed]

63. Tuinstra, F.; Koenig, J.L. Raman spectrum of graphite. J. Chem. Phys. 1970, 53, 1126-1130. [CrossRef]

64. Vázquez-Santos, B.M.; Geissler, E.; László, K.; Rouzaud, J.N.; Martínez-Alonso, A.; Tascón, J.M.D. Comparative XRD, Raman, and TEM study on graphitization of PBO-derived carbon fibers. J. Phys. Chem. C 2012, 116, 257-268. [CrossRef]

65. Pawlyta, M.; Rouzaud, J.N.; Duber, S. Raman microspectroscopy characterization of carbon blacks: Spectral analysis and structural information. Carbon 2015, 84, 479-490. [CrossRef]

66. Brownson, D.A.C.; Kampouris, D.K.; Banks, C.E. Graphene electrochemistry: Fundamental concepts through to prominent applications. Chem. Soc. Rev. 2012, 41, 6944-6976. [CrossRef]

67. Men, X.J.; Wu, Y.L.; Chen, H.B.; Fang, X.F.; Sun, H.; Yin, S.Y.; Qin, W.P. Facile fabrication of $\mathrm{TiO}_{2} / \mathrm{Graphene}$ composite foams with enhanced photocatalytic properties. J. Alloys Compd. 2017, 703, 251-257. [CrossRef]

68. Najafi, M.; Kermanpur, A.; Rahimipour, M.R.; Najafizadeh, A. Effect of $\mathrm{TiO}_{2}$ morphology on structure of $\mathrm{TiO}_{2}$-graphene oxide nanocomposite synthesized via a one-step hydrothermal method. J. Alloys Compd. 2017, 722, 272-277. [CrossRef]

69. Stengl, V.; Popelkova, D.; Vlacil, P. $\mathrm{TiO}_{2}$-graphene nanocomposite as high performace photocatalysts. J. Phys. Chem. C 2011, 115, 25209-25218. [CrossRef]

70. Tian, F.; Zhang, Y.; Zhang, J.; Pan, C. Raman Spectroscopy: A New Approach to Measure the Percentage of Anatase $\mathrm{TiO}_{2}$ Exposed (001) Facets. J. Phys. Chem. C 2012, 116, 7515-7519. [CrossRef]

71. Alsharaeh, E.H.; Bora, T.; Soliman, A.; Ahmed, F.; Bharath, G.; Ghoniem, M.G.; Abu-Salah, K.M.; Dutta, J. Sol-gel-assisted microwave-derived synthesis of anatase $\mathrm{Ag} / \mathrm{TiO}_{2} / \mathrm{GO}$ nanohybrids toward efficient visible light phenol degradation. Catalysts 2017, 7, 133. [CrossRef]

72. Pastrana-Martínez, L.M.; Morales-Torres, S.; Likodimos, V.; Falaras, P.; Figueiredo, J.L.; Faria, J.L.; Silva, A.M.T. Role of oxygen functionalities on the synthesis of photocatalytically active graphene- $\mathrm{TiO}_{2}$ composites. Appl. Catal. B Environ. 2014, 158-159, 329-340.

73. Yang, D.; Velamakanni, A.; Bozoklu, G.; Park, S.; Stoller, M.; Piner, R.D.; Stankovich, S.; Jung, I.; Field, D.A.; Ventrice, C.A.; et al. Chemical analysis of graphene oxide films after heat and chemical treatments by $\mathrm{X}$-ray photoelectron and micro-Raman spectroscopy. Carbon 2009, 47, 145-152. [CrossRef]

74. Pulido, A.; Concepcion, P.; Boronat, M.; Botas, C.; Alvarez, P.; Menendez, R.; Corma, A. Reconstruction of the carbon $\mathrm{sp}^{2}$ network in graphene oxide by low-temperature reaction with CO. J. Mater. Chem. 2012, 22, 51-56. [CrossRef]

75. Fan, W.; Lai, Q.; Zhang, Q.; Wang, Y. Nanocomposites of $\mathrm{TiO}_{2}$ and reduced graphene oxide as efficient photocatalysts for hydrogen evolution. J. Phys. Chem. C 2011, 115, 10694-10701. [CrossRef] 
76. Appavoo, I.A.; Hu, J.; Huang, Y.; Li, S.F.Y.; Ong, S.L. Response surface modeling of Carbamazepine (CBZ) removal by Graphene-P25 nanocomposites/UVA process using central composite design. Water Res. 2014, 57, 270-279. [CrossRef]

77. Orellana-García, F.; Álvarez, M.A.; López-Ramón, M.V.; Rivera-Utrilla, J.; Sánchez-Polo, M. Photoactivity of organic xerogels and aerogels in the photodegradation of herbicides from waters. Appl. Catal. B Environ. 2016, 181, 94-102. [CrossRef]

78. Chen, T.S.; Chiou, S.E.; Shiue, S.T. The effect of different radio-frequency powers on characteristics of amorphous boron carbon thin film alloys prepared by reactive radio-frequency plasma enhanced chemical vapor deposition. Thin Solid Films 2013, 528, 86-92. [CrossRef]

79. Liu, B.; Wen, L.; Zhao, X. The photoluminescence spectroscopic study of anatase $\mathrm{TiO}_{2}$ prepared by magnetron sputtering. Mat. Chem. Phys. 2007, 106, 350-353. [CrossRef]

80. Awfa, D.; Ateia, M.; Fujii, M.; Johnson, M.S.; Yoshimura, C. Photodegradation of pharmaceuticals and personal care products in water treatment using carbonaceous- $\mathrm{TiO}_{2}$ composites: A critical review of recent literature. Water Res. 2018, 142, 26-45. [CrossRef]

81. Hanaor, D.A.; Sorrell, C.C. Review of the anatase to rutile phase transformation. J. Mater. Sci. 2011, 46, 855-874. [CrossRef]

82. Shaham-Waldmann, N.; Paz, Y. Away from $\mathrm{TiO}_{2}$ : A critical minireview on the developing of new photocatalysts for degradation of contaminants in water. Mater. Sci. Semicond. Process. 2016, 42, 72-80. [CrossRef]

83. Ohno, T.; Tokieda, K.; Higashida, S.; Matsumura, M. Synergism between rutile and anatase $\mathrm{TiO}_{2}$ particles in photocatalytic oxidation of naphthalene. Appl. Catal. A Gen. 2003, 244, 383-391. [CrossRef]

84. Batzill, M.; Morales, E.H.; Diebold, U. Influence of nitrogen doping on the defect formation and surface properties of $\mathrm{TiO}_{2}$ rutile and anatase. Phys. Rev. Lett. 2006, 96, 026103. [CrossRef] [PubMed]

85. Hurum, D.C.; Agrios, A.G.; Gray, K.A.; Rajh, T.; Thurnauer, M.C. Explaining the enhanced photocatalytic activity of Degussa P25 mixed-phase $\mathrm{TiO}_{2}$ using EPR. J. Phys. Chem. B 2003, 107, 4545-4549. [CrossRef]

86. Khalid, N.R.; Ahmed, E.; Hong, Z.; Sana, L.; Ahmed, M. Enhanced photocatalytic activity of graphene-TiO 2 composite under visible light irradiation. Curr. Appl. Phys. 2013, 13, 659-663. [CrossRef]

87. Álvarez, M.A.; Ruidíaz-Martínez, M.; Cruz-Quesada, G.; López-Ramón, M.V.; Rivera-Utrilla, J.; Sánchez-Polo, M.; Mota, A.J. Removal of parabens from water by UV-driven advanced oxidation processes. Chem. Eng. J. 2020, 379, 122334. [CrossRef]

88. Guo, J.; Shi, H.; Huang, X.; Shi, H.; An, Z. AgCl/Ag $\mathrm{AO}_{4}$ : A stable Ag-Based nanocomposite photocatalyst with enhanced photocatalytic activity for the degradation of parabens. J. Colloid Interface Sci. 2018, 515, $10-17$. [CrossRef]

(C) 2020 by the authors. Licensee MDPI, Basel, Switzerland. This article is an open access article distributed under the terms and conditions of the Creative Commons Attribution (CC BY) license (http://creativecommons.org/licenses/by/4.0/). 